\title{
Resilience of Critical Infrastructure Systems to Floods: A Coupled Probabilistic Network Flow and LISFLOOD-FP Model
}

\author{
Yunzhu Yin ${ }^{1, *}$, Dimitri V. Val ${ }^{2}\left(\mathbb{0}\right.$, Qingping Zou ${ }^{2, *}$ (i) and Daniil Yurchenko ${ }^{3}(\mathbb{C}$ \\ 1 Department for Physical Oceanography and Instrumentation, Leibniz Institute for Baltic Sea Research \\ Warnemünde (IOW), Seestraße 15, 18119 Rostock, Germany \\ 2 School of Energy, Geoscience, Infrastructure and Society, Institute for Infrastructure and Environment, \\ Heriot-Watt University, Edinburgh EH14 4AS, UK; d.val@hw.ac.uk \\ 3 School of Engineering and Physical Sciences, Institute of Mechanical, Process \& Energy Engineering, \\ Heriot-Watt University, Edinburgh EH14 4AS, UK; d.yurchenko@hw.ac.uk \\ * Correspondence: yunzhu.yin@io-warnemuende.de (Y.Y.); q.zou@hw.ac.uk (Q.Z.); \\ Tel.: +49-1525-2020-484 (Y.Y.)
}

Citation: Yin, Y.; Val, D.V.; Zou, Q.; Yurchenko, D. Resilience of Critical Infrastructure Systems to Floods: A Coupled Probabilistic Network Flow and LISFLOOD-FP Model. Water 2022, 14, 683. https://doi.org/ $10.3390 / w 14050683$

Academic Editors: Koichiro Kuraji and Marco Franchini

Received: 31 December 2021 Accepted: 15 February 2022 Published: 22 February 2022

Publisher's Note: MDPI stays neutral with regard to jurisdictional claims in published maps and institutional affiliations.

Copyright: (C) 2022 by the authors. Licensee MDPI, Basel, Switzerland. This article is an open access article distributed under the terms and conditions of the Creative Commons Attribution (CC BY) license (https:// creativecommons.org/licenses/by/ $4.0 /)$.

\begin{abstract}
In this paper, a network-flow model was constructed to simulate the performance of interdependent critical infrastructure systems during flood hazards, when there is shortage of commodities such as electrical power and water. The model enabled us to control the distribution of commodities among different consumers whose demand cannot be fully met. Incorporating time-variance in the model allowed for evaluating the time evolution of the functional level of the infrastructure systems and quantifying their resilience. As a demonstration of the model's capability, the network model was coupled with a raster-based hydraulic flooding model in the way of Monte Carlo simulations. It was then used to investigate the cascading effects of flood-related failures of individual infrastructure assets on the performance of the critical infrastructure systems of a coastal community under different flooding scenarios and future climate impacts. The coupled modelling framework is essential for correctly assessing the interdependences and cascading effects in the infrastructure systems in the case of flood hazards. While in the considered example, the extent of inundation becomes less severe with a changing climate, the risk to infrastructure does not recede because of the cascading effects. This behaviour could not be captured by the flood model alone.
\end{abstract}

Keywords: infrastructure networks; urban flood; urban resilience; climate changes; sea level rise; natural hazard; flood modelling; LISFLOOD-FP; network flow model; cascading effects

\section{Introduction}

Critical infrastructure systems (CIs), such as electricity, water, and wastewater, provide the essential service for the well-being, safety, and economic growth of modern society. However, with the growing global population, expanded economy, and impacts of climate change, the CIs suffer from more frequent and severe failures due to ageing, increased loads, and man-made or natural hazards. Therefore, it is crucial to enhance the resilience of the CIs, in particular, to identify their key components and ensure their future uninterrupted functioning. Novel numerical modelling of the vulnerability of CIs to man-made and natural hazards provides a robust tool for developing efficient strategies for the improvement of the CIs' resilience and their adaption to climate change.

Ouyang [1] categorised the numerical models for simulating the interdependences of CIs into 6 types: empirical, agent-based, system dynamics-based, economic theory, network-based, and others not belonging to any of the above categories. The accuracy of the empirical and economic theory approaches depends on available data, which are usually difficult to obtain due to the complexity of the CIs. The system dynamic approach uses a series of differential equations to describe the behaviour, including the feedback loops derived from policy and decision-making, in a time series of system evolution. However, 
the validation of this approach is limited by available data. The bottom-up, agent-based approach models the complex behaviours of the participants of the interdependent CIs and decision makers with discrete-event simulation. Although it is widely used by many wellknown research laboratories (e.g., Aspen-EE in Sandia National Lab (Albuquerque, NM, USA), SMART in Argonne National Lab (Lemont, II, USA)), it may be difficult to justify the assumptions controlling the agents' behaviours by theoretical or statistical models that may affect the accuracy of obtained results. A lack of data and difficulty in modelling agents' behaviours are also the main challenges [1]. Other widely applied approaches include hierarchical holographic modelling, high level architecture-based modelling, Petri nets, and Bayesian networks [2-4]. The hierarchical holographic modelling is a holistic method for capturing the attributes of CIs, for understanding risks at different levels, while high level architecture-based modelling treats CIs as a system-of-systems at multiple levels with a distributed simulation environment. The Petri-net based model considers the flow of tokens placed in a net that is represented by four-tuple to account for the CIs interdependencies. All these approaches/models seem to be of high complexity regarding their applications to interdependent CIs. Bayesian networks use nodes to represent random variables and edges for conditional dependencies, which is a convenient probabilistic analysis, but a lack of logical connections between the nodes and edges may impede the model's application.

Results of numerical simulations of the CIs performance, including the cascading effects of damage and failures of the infrastructure components (e.g., electricity substations), may be very helpful for developing efficient strategies for reducing the vulnerability and improving the resilience of the CIs to hazards and climate change. A numerical model for this purpose needs to satisfy several requirements. First, the model should be able to account for the interdependencies between different components of the infrastructure systems. Second, since the conditions and demands on infrastructure may evolve rapidly during and after interruptions due to hazard events; it is also important for the model to capture the evolution of the infrastructure performance over time, for which a timedependent dynamic model is required. Third, to analyse the small-scale subsystems and components of the CIs, the model should have a relatively high resolution, so that it could be implemented at multiple layers, either hierarchically or homogeneously. Finally, since there are large uncertainties associated with the prediction of demands on infrastructure and its behaviour under these demands, it is an advantage to use a probabilistic model capable of accounting for such uncertainties.

Network flow models seem to satisfy all the aforementioned requirements. In these models, nodes represent different CI components, while links/edges connecting these nodes stand for connections between the components, through which the exchange/flow of commodities between the components takes place (either at the same layer or across different layers). The propagation of cascading failures within and across the infrastructure systems can be simulated with relative ease in such models. One of the advantages of network flow models is that the same mathematical functions can describe the commodity flow in different systems such as power, water, and gas [5]. Thus, it is much easier to connect different systems together to consider the interdependences between them. However, the traditional network flow model only ensures the continuity of the commodities' flow and ignores the physical laws governing the time variant flow [6]. Val et al. [5] extended this model to consider the storage of commodities in each node and simulate the performance of the system in a probabilistic fashion based on the time-variant formulation proposed by Svenedsen and Wolthusen [7]. Uncertainties associated with damage of infrastructure assets can be assessed by introducing a multifunctional node to consider the production, consumption, trans-shipment, and storage of commodities. These variables enable researchers to represent the functioning of infrastructure systems, especially damaged systems, much more realistically when compared to the traditional network flow model. For example, the model allows one to consider that potable water (as a commodity) can be produced by water plants, consumed by residents, trans-shipped through water 
pumping stations, stored in water towers and reservoirs, and that electricity is required for the operation of the water plants and pumping stations. However, the requirement of probabilistic input related to a hazard event (e.g., probability distributions of flood inundation depths) restricted the model's application to hypothetical case studies and limited its further development.

As noted by Val et al. [5], the probability of each node operation in the case of a flood hazard is based on the probability distribution of flood depths, which is one of the motivations to introduce a flood model into the present study for the first time. For this purpose, we applied a raster-based, physical-reduced 2D hydraulic model, LISFLOODFP $[8,9]$, to a coastal town in the UK to predict a compound river and coastal flood condition and its implications on the infrastructure systems. This raster-based model evaluates the flooding inundation based on digital elevation model (DEM) topography, which could consider coastal inundation, river flooding, etc. We ran the LISFLOOD-FP model using ensemble boundary conditions based on Monte Carlo simulations to produce sufficient river and coastal flooding scenarios in order to derive the probabilities of flood depth at each node of the infrastructure network under consideration.

Similarly to Val et al. [5], we considered a time-variant formulation of the problem, in which the cost optimisation analysis was performed at each time step and the continuity between the time steps was imposed through constraints on the storage variables. In comparison to Val et al. [5], we considered unmet demands for commodities in an innovative way, by allowing bi-directional flows and loops in networks and introducing a step-wise cost for the unmet demands. Uncertainties associated with the predicted demands on commodities were quantified and included in a probabilistic analysis. The proposed model is more efficient and robust than the majority of agent-based models, as it does not need to model complex human behaviours. Furthermore, its computational time is far less than for many other models due to the identical mathematical description of the flows of different commodities. Finally, we coupled the network flow model with the LISFLOOD-FP model to investigate the cascading effects within the critical infrastructure systems under different river and coastal flooding scenarios and climate impacts. The coupled model was applied to examine the vulnerability of the CIs (electricity and wastewater) of a coastal town in the UK. The probability of inundation depth in each node of the network were provided by the flood model in combination with Monte Carlo simulation. Therefore, this coupled framework is able to quantify the level of functionality, risk, and resilience of the CIs during a natural hazard such as flooding and, in principle, can be applied to other coastal communities susceptible to flooding.

The rest of the paper is organised as follows: the methodology of the network flow model (including its changes compared to Val et al. [5]) and the flood model setup for a variety of scenarios, including future climate change, are introduced in Section 2 . The results of the analysis and their discussion are presented in Section 3, followed by conclusions in Section 4.

\section{Methods and Data}

Two numerical models were coupled in this study: an infrastructure network flow model, and a hydraulic flood model, whose results could be fed into the infrastructure model in the form of statistical data. These models are described in detail in the following subsections.

\subsection{Improved Infrastructure Network Flow Model}

A network model is the type of a system model suitable for the investigation of urban resilience to hazards and climate change [5,10-14]. In this study, the infrastructure network flow model in Val et al. [5] is extended to consider bi-directional flows between nodes, networks with loops, and step-wise costs of unmet demands. The bi-directional flows have been made possible by introducing two unidirectional links (in the opposite directions) between connected nodes that also enable us to switch the sink and source nodes. Of course, 
this should be done in accordance with the physical laws controlling the flow of a particular commodity. For example, for electricity, the bi-directional flow is only possible between nodes operating at the same voltage.

The introduction of bi-directional flow between nodes also makes it possible to consider loops, which are usually present in various infrastructure networks (e.g., electricity, water, transport). The loops are essential for the functioning of a network when the latter is damaged by a hazard. An issue that may arise from the inclusion of loops into a network is a possibility that the network flow optimisation problem has more than one solution. However, this usually does not occur when the costs of commodity flows are proportional to the lengths of the physical connections (e.g., electricity transmission and distribution lines, water pipes) represented by the links; even if this does occur, it can easily be fixed by assigning slightly different flow costs to two opposite direction links, which connect a pair of nodes in the loop (and by that to define a preferable direction of the commodity flow in the undamaged network).

The step-wise costs of unmet demands are needed to control the distribution of a commodity between its consumers when the network is damaged and demand for the commodity exceeds its supply. Thereby, the further away the consumers from the source of the commodity the less their demand for the commodity is satisfied (as a result of the solution of the network flow optimisation problem). As in Val et al. [5], the time-dependent behaviour of a network in the extended model was considered through discreet time-steps, and extra variables (compared to the traditional network flow model) were introduced to represent the production, trans-shipment, unmet demands, and storage of commodities. The extended network flow model is described in more detail in the following subsections.

\subsubsection{Extended Network Flow Model}

The nodes represent the infrastructure components/assets associated with the productions, consumption, trans-shipment, and storage of commodities; these include electricity substations, water, and sewage plants, as well as hospitals or residential buildings. In general, the infrastructure components can be in physical, cyber, geographical, or logical, and can interact with each other. The nodes are connected by links/edges, by which the interaction between the infrastructure components, usually in the form of the flow of commodities, is modelled. A network can be either balanced (when demand for commodities is equal to their supply) or unbalanced (when the demand exceeds the supply). In the latter case, unmet demand for a commodity or commodities occurs initially in one or more nodes, which then may have a cascading effect on other parts of the network.

The traditional network flow model can be used to optimise the performance of an undamaged balanced infrastructure system, which is presented as a network with $V$ nodes and $E$ edges, by solving the following linear programming problem that minimises the total operational cost of the system, $C$ [15]:

$$
\begin{gathered}
\text { minimise } C=\sum_{e \in E} c^{f, e} f_{e} \\
\text { subject to }: f^{i \leftarrow}-f^{i \rightarrow}=k^{i} \forall i \in V \\
\text { and } 0 \leq f_{e} \leq f_{e}^{\max } \forall e \in E
\end{gathered}
$$

where $f_{e}$ and $f_{e}^{\max }$ are the flow rate of community on edge $e$ and the maximum flow capacity of this edge, respectively; $c^{f, e}$ is the cost associated with this flow; $f^{i \leftarrow}$ and $f^{i \rightarrow}$ are the in-flow and out-flow rates at node $i$, respectively; $k^{i}$ is the demand/supply rate of the commodity at node $i$. This traditional model cannot deal with unbalanced infrastructure systems, as well as accounting for such essential features/functions of infrastructure systems as storage and production. To deal with unbalanced (i.e., damaged) infrastructure systems and simulate more realistically their operation, including interdependencies, additional variables, representing unmet demands, storage, production, and trans-shipment, were introduced into the network flow model, and then a linear programming optimisation 
problem, which included these variables, was formulated in [5]. The formulation was also time-variant, which allowed us to simulate the performance of infrastructure systems from the moment of their damage by a particular hazard until their complete recovery. The full formulation of this extended model (see [5]) will not be reproduced herein; instead, we will concentrate on the elements of the model which have been changed/improved in the present study.

To illustrate the model changes made herein, we considered an electricity network in a small coastal town in the UK, shown in Figure 1. As can be seen, the network includes several loops, which need to be kept in the model since they ensure the network redundancy. The latter is essential for the network functioning in the case of damage. To account for the redundancy provided by the loops, two opposite direction edges need to be introduced in the model for each connected pair of nodes in the loops. In this way, the reverse of the flow of electric current in the loops can be modelled. It is important to note that all nodes in the network operate at the voltage of $11 \mathrm{kV}$, except for the node in the lower-right quarter of the map, which represents a $132 \mathrm{kV}$ substation (Figure 1). For this network, the optimisation problem formulation from [5] can be significantly simplified and expressed as:

$$
\begin{gathered}
\text { minimize } C=\sum_{e \in E} c^{f, e} f_{e}+\sum_{i \in V} c^{U, i} U^{i} \\
\text { subject to }: \sum f^{i \leftarrow}-\sum f^{i \rightarrow}+U^{i}=k^{i} \forall i \in V \\
\text { and } 0 \leq f_{e} \leq f_{e}^{\text {max }} \forall e \in E ; 0 \leq U^{i} \leq k^{i} \forall i \in V
\end{gathered}
$$

where $U^{i}$ is the unmet demand in $i$ node; $c^{U, i}$ is the cost of this unmet demand per unit.

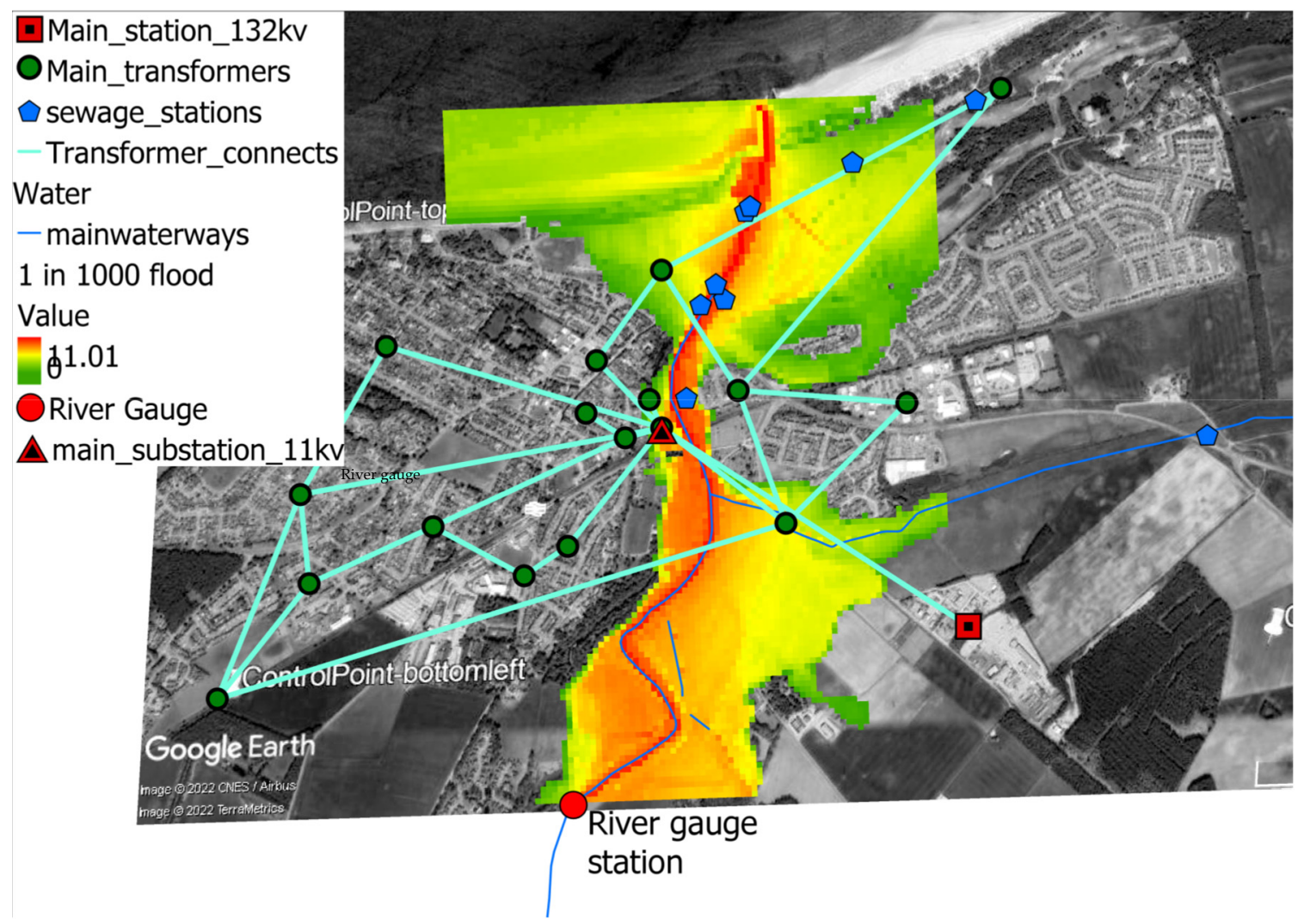

Figure 1. The network system and geographic locations of CIs in a small coastal town in the UK (the name and coordinates are not shown to ensure confidentiality). The cyan lines show the links in the simplified network model; the shaded areas are inundated areas for a 1 in 1000 year flooding event. The red dot indicates the location of the river gauge. See all the legend in the figure. 


\subsubsection{Network with Loops}

We began the consideration of the changes to the model in more detail with the analysis of networks with loops. Initially, we considered very simple networks with three to four nodes, as shown in Figure 2. In this figure, circles with numbers inside represent nodes; arrows-directional links/edges, which are denoted as $\mathrm{X} 1, \mathrm{X} 2, \ldots$; two links in the opposite directions between a pair of nodes will be further referred to as a bidirectional arc (e.g., links X3 and X4 between Nodes 2 and 3 in Figure 2a, respectively). We considered only unbalanced (i.e., damaged) networks. In all three networks, Node 1 is the source of the commodity; there are unmet demands in other nodes, which will be denoted as U1, U2, ... (e.g., U1 denotes unmet demand in Node 2). The costs of flow in the links and unmet demand in the nodes will be denoted as C(name of link/unmet demand), e.g., $C(X 1)-$ cost of flow in link X1, C(U1)-cost of unmet demand U1.

(a)

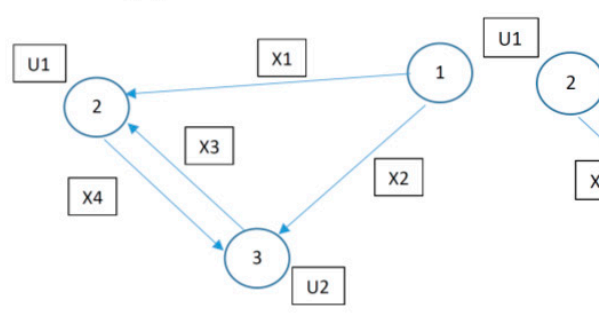

(b)

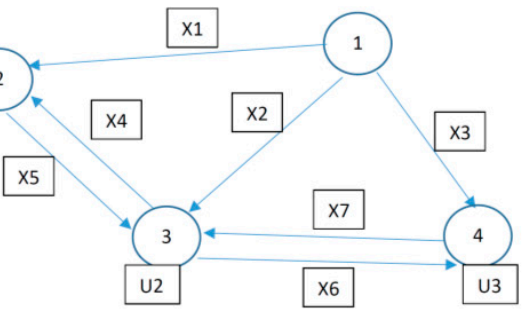

(c)

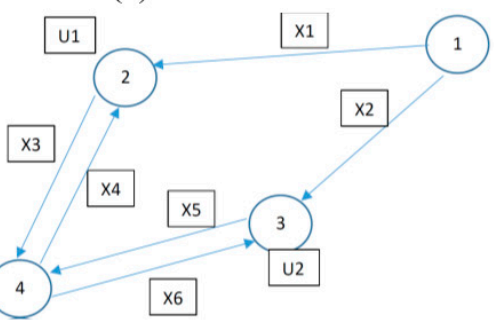

Figure 2. Simple networks with loops. The variables are marked in the rectangles. The node numbers are in circles. (a) three-node case; (b) four-node case 1 ; (c) four-node case 2.

Using the three simple networks shown in Figure 2, we will illustrate how the costs of flow in the edges and the costs of the unmet demands in the nodes affect the distribution of a commodity in an unbalanced network and the flow directions in bidirectional arcs. For example, in the network shown in Figure 2a, when the network is undamaged and the cost of flow in its edges is simply proportional to the length of the physical connections modelled by these edges, the commodity will flow from Node 1 (source) to Nodes 2 and 3 (consumers) via edges $X 1$ and $X 2$. However, if edge $X 1$ is damaged and the flow through it is either impossible or its costs significantly increase, so that $C(X 1)>C(X 2)+$ $\mathrm{C}(\mathrm{X} 3)$, then edge $\mathrm{X} 3$ in the bidirectional arc becomes active (i.e., the pathway from Node 1 to Node 2 is via edges $X 2$ and X3). In a similar way, if edge $X 2$ is damaged, then the commodity will flow through edges $\mathrm{X} 1$ and $\mathrm{X} 4$ (i.e., edge $\mathrm{X} 4$ becomes active). The costs of unmet demands do not affect the flow pathways; however, they affect the distribution of a commodity between the consumers. For example, if the costs of unmet demands U1 and $\mathrm{U} 2$ are the same (i.e., $\mathrm{C}(\mathrm{U} 1)=\mathrm{C}(\mathrm{U} 2)$ ) and edge $\mathrm{X} 1$ is damaged, then the shortage of the commodity will always be more severe in Node 2 . This means that as long as the supply from Node 1 exceeds the demand in Node 3, there will be no unmet demand in Node 3 , while the amount of the commodity received by Node 2 will be the supply minus the demand in Node 3; when the supply is less than or equal to the demand in Node 3, Node 2 will stop receiving any commodity. In order to avoid that, the costs of unmet demand should be different. Selecting $\mathrm{C}(\mathrm{U} 1)>\mathrm{C}(\mathrm{U} 2)$, we can redistribute unmet demand equally between Nodes 2 and 3; by further increasing C(U1), we can prioritise Node 2 so that its demand is fully met until it is possible and then it receives all available supply, while Node 3 receives nothing.

In the 4-node network in Figure 2b, the edges in the two bidirectional arcs will not be activated as long as the costs of flow in the edges are proportional to the actual lengths of the connections (i.e., the commodity flow from Node 1 -source will be via edges X1, X2, and $\mathrm{X} 3)$. In this case, if $\mathrm{C}(\mathrm{U} 1)=\mathrm{C}(\mathrm{U} 2)=\mathrm{C}(\mathrm{U} 3)$, the distribution of unmet demand will depend on the costs of flow: $C(X 1), C(X 2)$, and $C(X 3)$. For example, if $C(X 1)>C(X 2)>$ $\mathrm{C}(\mathrm{X} 3)$, then $\mathrm{U} 1$ will increase first, followed by $\mathrm{U} 2$, and then $\mathrm{U} 3$. To change the distribution 
of unmet demand between the nodes, the costs $\mathrm{C}(\mathrm{U} 1), \mathrm{C}(\mathrm{U} 2)$, and $\mathrm{C}(\mathrm{U} 3)$ need to be unequal. For example, to prioritise the supply of Node $2 \mathrm{C}(\mathrm{U} 1)$ should be set higher than C(U2) and $\mathrm{C}(\mathrm{U} 3)$. Damage to the network can lead to activation of the edges in the bidirectional arcs. For example, if $\mathrm{X} 2$ is damaged (i.e., fails completely or $\mathrm{C}(\mathrm{X} 2)$ becomes very high), then the flow pathway from Node 1 to Node 3 may be either via $X 1$ and $X 5$ when $C(X 1)+C(X 5)>$ $C(X 3)+C(X 7)$, or via $X 3$ and $X 7$ otherwise. Eventually, the activation of the edges in the bidirectional arcs and resulting flow pathways depend on damage caused to the network and the costs of flow in the edges.

The 4-node network shown in Figure $2 \mathrm{c}$ can illustrate the case when a single solution does not exist. If $C(X 1)+C(X 3)=C(X 2)+C(X 5)$ and the flow capacities of the edges are large enough so that the corresponding constraints remain inactive, then the optimisation problem of minimising the flow cost has two possible solutions. To avoid such a situation, one of the costs of flow in the edges should be slightly changed. It is worth noting that the possibility of such a problem's occurrence in networks representing real infrastructure systems, especially when the flow costs are proportional to the lengths of the physical connections, is very low. To supply a commodity to Node 4 when $C(X 1)+C(X 3)<C(X 2)$ $+C(X 5)$, edge $X 3$ will be activated, and X5 otherwise. If edge X1 is completely damaged, the flow of the commodity will be through edges $X 2, X 5$, and $X 4$. As in the other two networks, to control the distribution of the commodity in the unbalanced network (i.e., supply of the commodity is less than its total demand) the costs of unmet demands, C(U1), $\mathrm{C}(\mathrm{U} 2)$, and $\mathrm{C}(\mathrm{U} 3)$, should be set in accordance to specified priorities.

\subsubsection{Extension of the Model Capability}

As is clear from the examples of the simple networks in the previous section, the activation of bidirectional arcs depends on the flow costs of edges, while the distribution of commodities between consumers in unbalanced networks can be controlled by the costs of unmet demands. To further illustrate the extended network flow model, in particular, its coupling with a flood model, we considered an electricity network in a small town in the UK (and further in the paper, its interaction with a sewage network). This is a low-voltage distribution network with a nominal voltage of $11 \mathrm{kV}$. The town suffered from flooding in the past and is susceptible to flooding in the future. Since this is a coastal town with a river flowing through it, the town is in danger of both river and coastal flooding; the lowland areas are particularly at risk, where a large caravan park and a major electricity substation (see Figure 1) are located. The actual electricity network has been simplified-several distribution lines are assumed to be straight, but the loops appearing in the network have been mainly preserved (see Figures 1 and 3). The lengths of the straight lines have been assigned in such a way that the relative differences between these lines remain the same as such differences between the corresponding lines in the original layout. Hence, the simplifications should not have any noticeable effects on the results of the network analyses. The notation in Figure 3 is similar to that in Figure 2, except that the unmet demands in the consumer nodes (from 2 to 17) are denoted as $X 41, X 42, \ldots, X 56$. The major electricity substation, treated as the source of the electrical power in the network, is represented by Node 1 . In order to consider redundancy in the network provided by the loops, several bidirectional arcs have been introduced, which allow switching the direction of the electric current flow in the loops. 


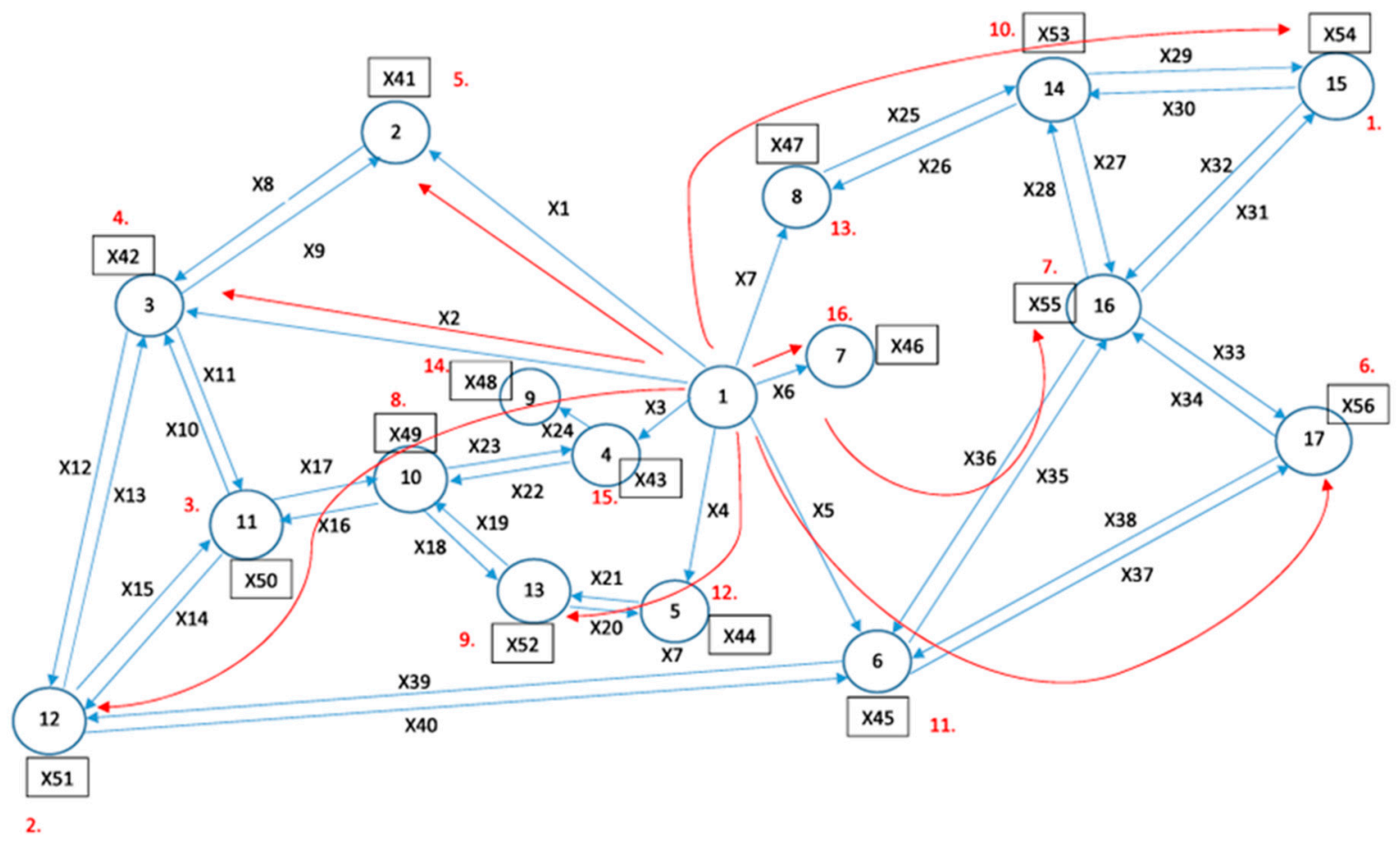

Figure 3. Simplified electricity network in a small town (blue lines); red lines show the flow pathways in the solution, when the flow costs in the edges are proportional to their actual lengths and the costs of unmet demands are the same for all nodes. The red numbers show the sequence in which the nodes stop to receive electrical power as the supply at Node 1 gradually decreases.

Initially, we assumed that the costs of flow in all edges were proportional to the lengths of the edges and the costs of all unmet demands were the same (scenario S0 in Table A1 in Appendix A). The solution for this case (i.e., the minimum cost flow pattern) is shown in Figure 3 by red lines, while the red numbers near the nodes along the lines indicate the sequence in which the nodes stop receiving electricity, as the supply in Node 1 gradually decreases at the rate of $10 \%$ per hour due to an accident/hazard (see Figure 4). The results show that Node 15, which is the farthest node from the electricity substation (i.e., Node 1-source), will be the first one without electricity in $3 \mathrm{~h}$ after the accident (see Figures 3 and 4). It will be followed by Node 12-the second farthest node from the source (in $4 \mathrm{~h}$ after the accident), and so on. The last nodes left without electricity, in $11 \mathrm{~h}$ after the accident, are Nodes 4, 9, and 7, which are the closest nodes to the source. Thus, it can be seen that the loss of the electricity supply in the consumer nodes occurs consecutively, i.e., node by node, and the sequence depends on the length of the links between the consumer nodes and the source. This means some consumers will be without electricity much longer than others (e.g., the consumers represented by Node 15 will be without electricity $8 \mathrm{~h}$ longer than those related to Nodes 4, 7 and 9); this may be unacceptable if Node 15 is an important asset. 


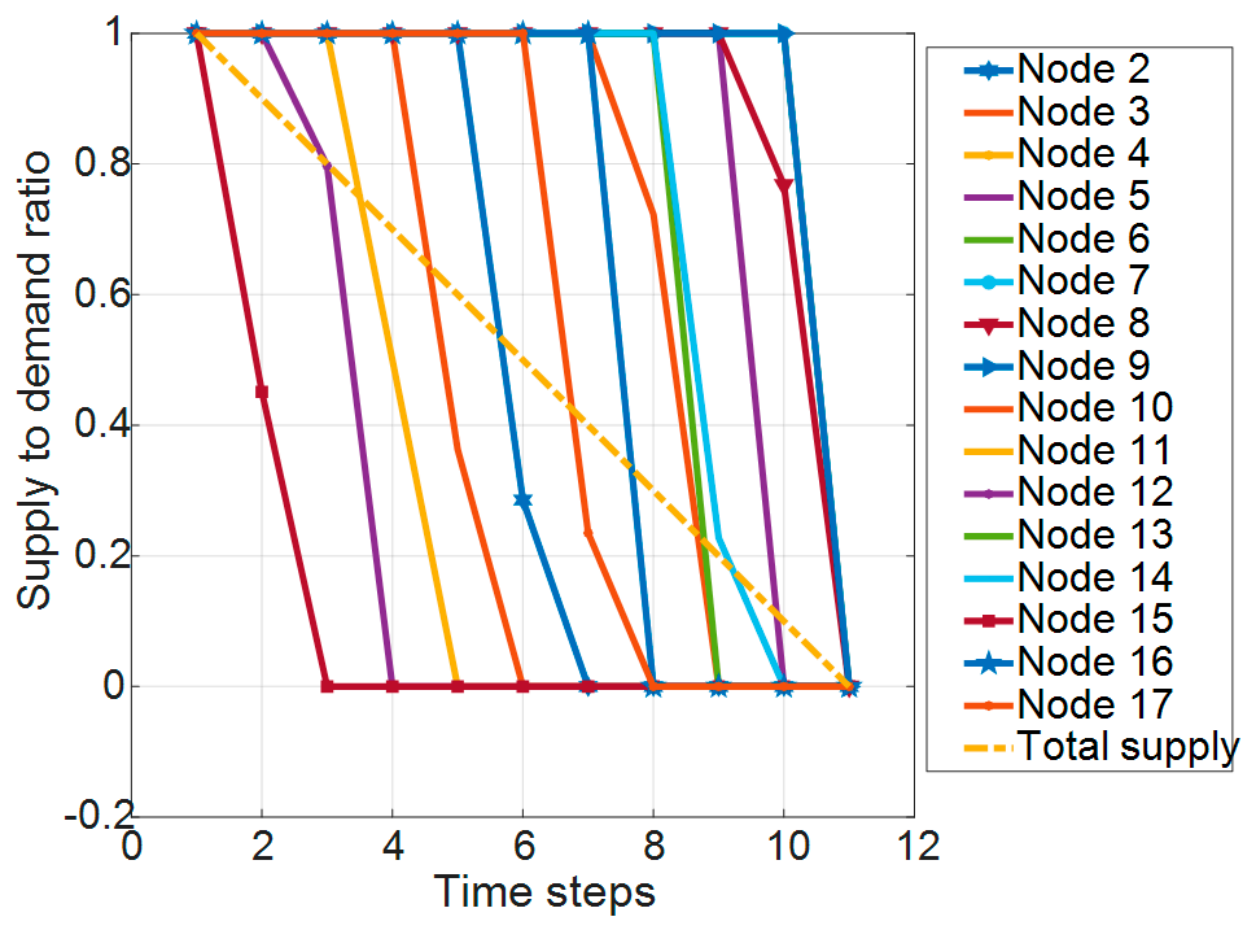

Figure 4. The percentage of demand supplied to each consumer node of the network (Figure 3) under $10 \%$ /hour reduction of the total supply for the baseline case (scenario S0 in Table A1).

When the costs of unmet demands among the consumer nodes are different, the order in which these nodes stop receiving the electrical power, as its supply decreases, can be changed. For example, when the cost of unmet demand for Node 15 (X54) is set at a higher value than such costs for the other nodes, Node 12 may become the first one to be left without electricity. However, the sequential character of the process in which the consumer nodes lose their electricity supply does not change. Therefore, if we simply modify the costs of unmet demands for different nodes, there are still nodes without electricity much longer than others following the one-by-one pattern, although the order is changed.

Each node in the network model contains real-life consumers (e.g., residential houses, shops, hospitals, water or wastewater pumping stations, etc.). It is considered to be highly undesirable for some consumers to be prioritised over others because of their locations. Moreover, some nodes may comprise critical infrastructure assets (e.g., hospitals, water/wastewater pumping stations, petrol stations), which need electricity to maintain at least some basic operations as long as it is still possible. For example, Node 15 includes a sewage treatment plant (see Figures 1 and 3), which uses about $80 \%$ of the total electricity consumption at this node. Since functioning of this sewage treatment plant is critical for the whole town, electricity should be supplied to the node for maintaining at least the basic operations of this plant as long as it is still possible. There are critical infrastructure facilities also in some other nodes of the network. Node 13 contains a hospital, which consumes about $40 \%$ of the total demand for electricity in this node, while Node 14 comprises a sewage pumping station, which consumes about $10 \%$ of the electricity demand in this node. It is essential to supply electricity to these facilities, for as long as possible, when the electricity network is unbalanced (e.g., due to damage caused by flooding). This means it is necessary to be able to control the distribution of electricity between the nodes, maintaining its supply at certain levels for each node, when the network becomes unbalanced. As shown previously, this cannot be done by simply setting different but constant costs of unmet demands for different nodes.

To solve the above problem, we describe the cost of unmet demand by a stepwise function; i.e., we divide unmet demand in node $i, U^{i}$, into $J(i)$ sub-total unmet demands $U_{j}^{i}$ so that $\sum_{j \in J(i)} U_{j}^{i}=U^{i}$, and for each sub-total unmet demand $U_{j}^{i}$, we introduce its individual 
$\operatorname{cost} c_{j}^{U, i}$. The optimisation problem given by Equations (4)-(6) is then reformulated in the following way:

$$
\begin{gathered}
\text { minimise } C=\sum_{e \in E} c^{f, e} f_{e}+\sum_{i \in V}\left(\sum_{j \in J(i)} c_{j}^{U, i} U_{j}^{i}\right) \\
\text { subject to } \sum f^{i \leftarrow}-\sum f^{i \rightarrow}+\sum_{j=1}^{J} U_{j}^{i}=k^{i} \quad \forall i \in V \& \forall j \in J(i) \\
\text { and } k^{i} \sum_{l=1}^{j-1} k_{l}^{i}<U_{j}^{i} \leq k^{i} \sum_{l=1}^{j} k_{l}^{i} \quad \forall i \in V \& \forall j \in J(i)
\end{gathered}
$$

where $k_{l}^{i}(l=1, \ldots, j)$ are the relative bounds of the sub-total unmet demands $U_{j}^{i}$ at node $i$, e.g., $k_{1}^{i}=0.2$ means that $0 \leq U_{1}^{i} \leq 0.2 k^{i}$ (i.e., $U_{1}^{i}$ does not exceed $20 \%$ of the demand rate $k^{i}$ of the commodity at node $\left.i\right), k_{2}^{i}=0.4$ then means that $0.2 k^{i}<U_{2}^{i} \leq(0.2+0.4) k^{i}$, and so on; the sum of $k_{j}^{i}$ should be equal to unity, i.e., $\sum_{j=1}^{J(i)} k_{j}^{i}=1$.

Using this new formulation of the network flow problem, we can control the distribution of a commodity between different nodes over time, as the available supply of the commodity decreases. The selection of the number of sub-total demands and their bounds for each node depends on what needs to be achieved. For example, we may aim to ensure that critical infrastructure facilities in various nodes of the network receive a sufficient amount of a commodity for their operation as long as this is still possible, i.e., as long as the remaining supply of the commodity is not less than its demand by these critical facilities. In the network shown in Figure 3, Node 15 contains a sewage treatment plant, which consumes about $80 \%$ of the electricity demand of this node. The unmet demand at this node can then be divided into two sub-totals- $U_{1}^{15}$ and $U_{2}^{15}$, with $k_{1}^{15}=0.2$ and $k_{2}^{15}=0.8$. If the cost of $U_{2}^{15}$ is set noticeably higher than that of $U_{1}^{15}$ and of the unmet demands at other nodes, this means that after the unmet demand at this node exceeds $20 \%$ of the node's demand, the electricity supply to this node will be prioritised when compared to the other nodes, i.e., the sewage treatment plant will continue to receive sufficient electricity for its operation (of course, until the total electricity supply in the network drops to the demand of this plant). The unmet demand at Node 13, which comprises a hospital that requires about $40 \%$ of the node's electricity demand, can be treated in a similar way. It can be divided into two sub-totals- $U_{1}^{13}$ and $U_{2}^{13}$, with $k_{1}^{13}=0.6$ and $k_{2}^{13}=0.4$. If the hospital and the sewage treatment plant are considered equally important to the town, then the cost of $U_{2}^{13}$ should be similar to that of $U_{2}^{15}$, and higher than the costs of the unmet demands at other nodes; however, if it is decided that the hospital is more important than the sewage treatment plant, then the cost of $U_{2}^{13}$ should be higher than that of $U_{2}^{15}$.

In the following, we examine how the distribution of electricity in the network shown in Figure 3 can be controlled by selecting different sub-total numbers of unmet demands and their bounds when the network becomes unbalanced. We started with a simple case, in which we divided the unmet demand at each consumer node into two sub-totals-U1 and U2. The costs of the first sub-total are set up one order lower than that of the second sub-total, so that the electricity supply to the most important infrastructure assets in each node, which are related to U2, is prioritised (it is assumed that each node contains critical infrastructure assets, which have higher priority than other consumers). For example, the most important infrastructure assets in the first-interrupted node (e.g., Node 15) are always supplied, while the relatively less important consumers in that node are in shortage. The two-layer profile scenarios are shown in Figure 5. It was assumed that total electricity supply drops by $10 \%$ hourly, which means that all nodes will be without electricity after $11 \mathrm{~h}$, as shown in Figure 4. For scenario S14 (Figure 5a), the first-interrupted node (Node 15) could maintain $60 \%$ of its electricity demand for an extra $3 \mathrm{~h}$, while the other nodes are interrupted partially when compared with the normal one-by-one case (Figure 4). This means, for example, under the interruption, the sewage treatment plant can operate for extra $3 \mathrm{~h}$, even when the total supply is in shortage continuously. Then, other CIs in Node 12 could have the electricity supply for $7 \mathrm{~h}$ rather than $4 \mathrm{~h}$ as in the baseline 
case (Figure 4). This is similar for scenarios S15 (Figure 5b), but with different distributed weights between the two sub-total costs. Therefore, the introduction of stepwise costs for unmet demand at each node could control the redistribution of the commodities in the unbalanced network system, which is in analogue to a division of multiple layers in neural network. This could increase the capability of controlling the system by human intervention or hazards, for example, by asking the residents to reduce less important consumptions if feasible; or the demands of one community would be reduced due to flooding.

Therefore, we could expect that the more layers we introduce for the cost profiles, the slower the supply to each node with higher priority assets is interrupted, to ensure that these higher priority assets remain in basic operations as long as possible. All other scenarios representing different cost step profiles are listed in Table A1. The selected solutions are shown in Figure 5, in which we explore how the changes of cost profile affect the entire CIs' system. We introduced several scenarios by dividing costs into $2,3,4$, and 5 sub-total costs in percentage (Table A1) and the sum of these percentages should be 1 . For example, for S15 scenario, 20\% for first cost, 80\% for second cost (Figure 5b); for S32 scenarios (4 sub-costs), 20\% for first cost, $40 \%$ for second cost, $20 \%$ for third cost, and $20 \%$ for fourth cost (Figure 5e). Therefore, by changing these cost profiles, the performance of each node would be changed accordingly.

Generally, it is shown that the supply-to-demand ratio at each node is proportional to the cost allocated to each sub-total of unmet demand. For example, the four subcost scenario (S3) leads to the supply reduction at each node within four steps, rather than the dramatic one-step drop as seen in the one-by-one case (i.e., S0). This gradual reduction in the electricity supply enables to support the basic functioning of critical infrastructure assets at each node for a few extra hours, which gives more time for responses, to mitigate consequences of a hazard. This also improves the resilience of CI assets during extreme events.

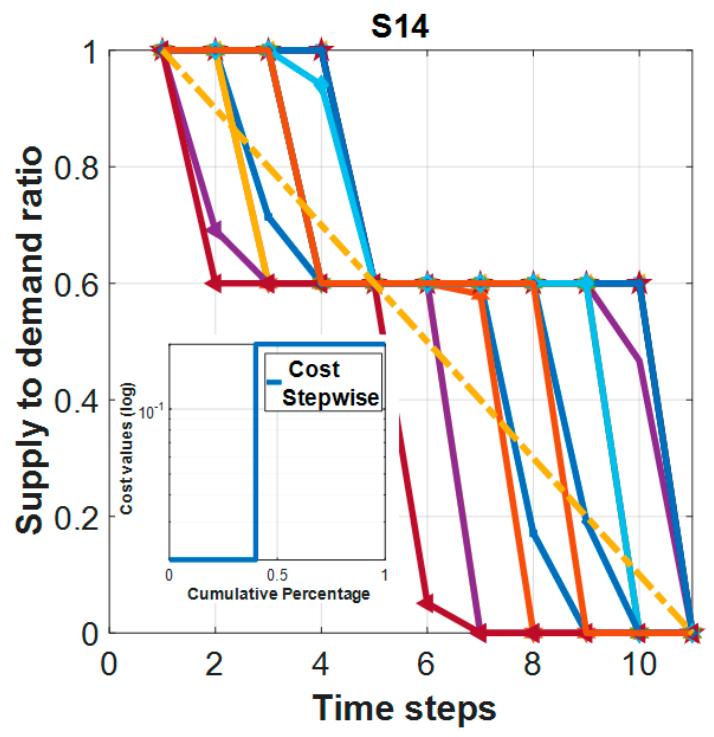

(a)

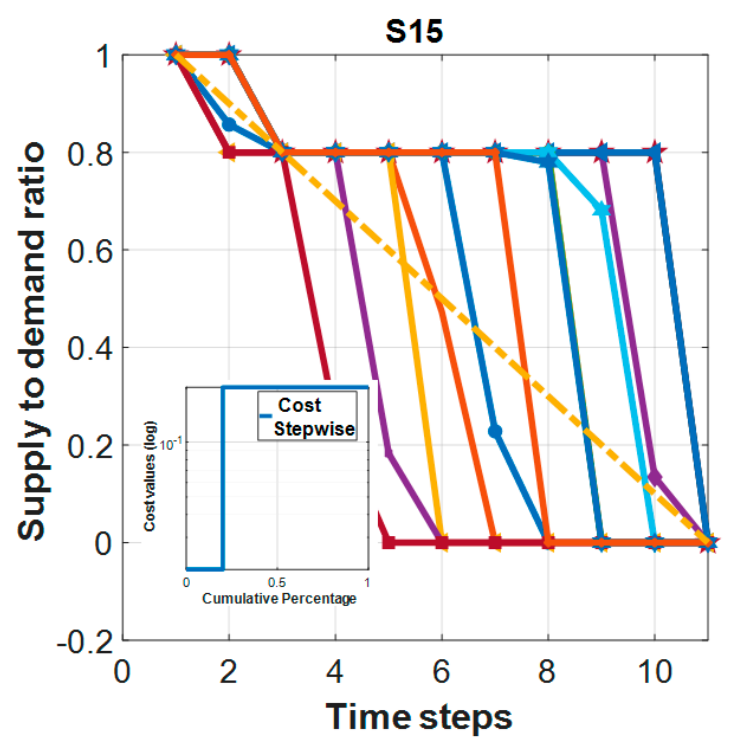

(b)

Figure 5. Cont. 


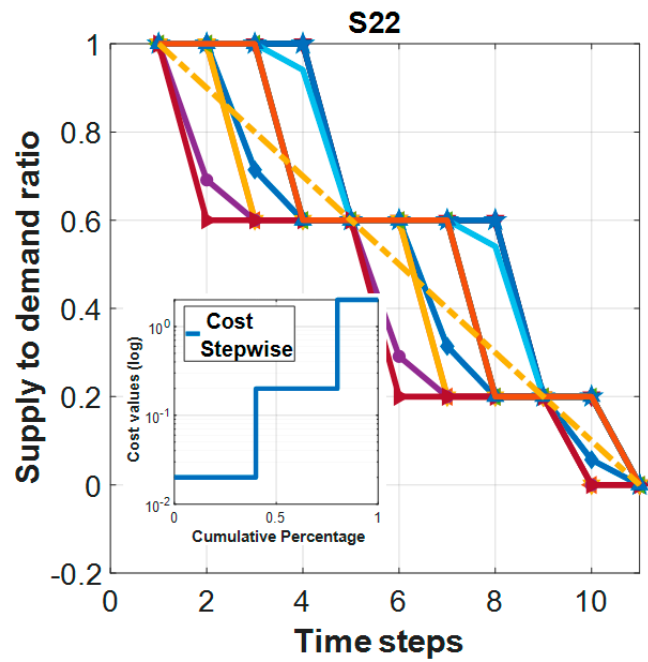

(c)

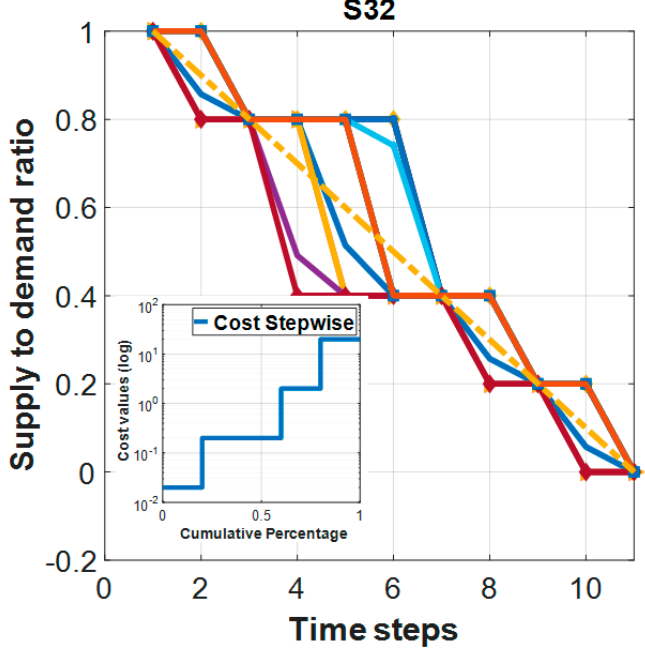

(e)

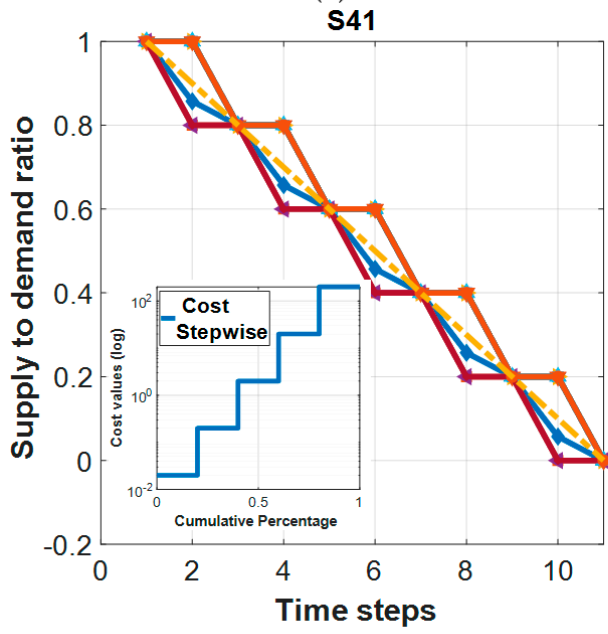

(g)

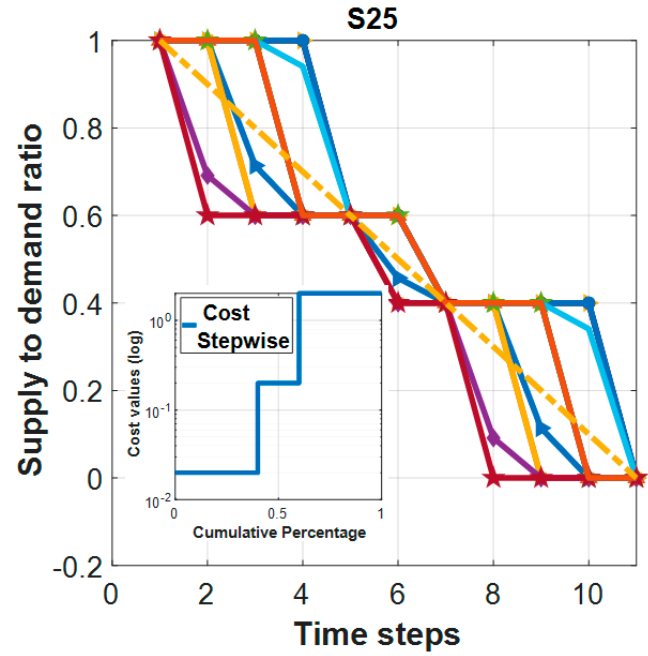

(d)

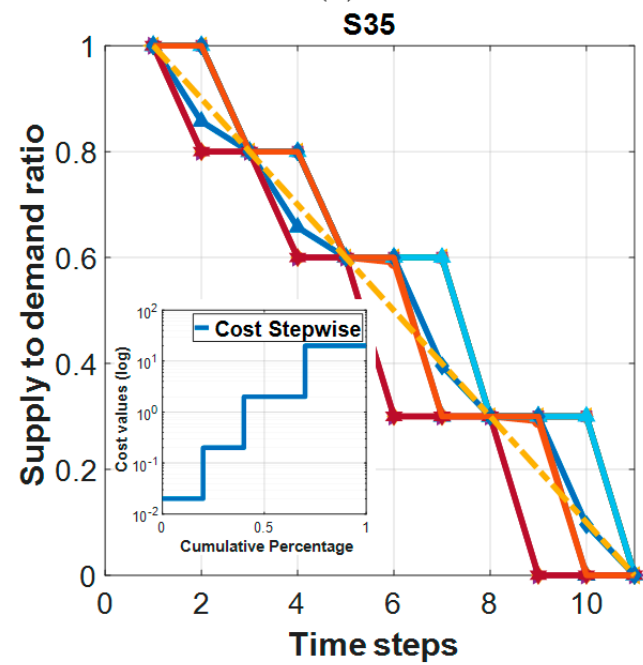

(f)

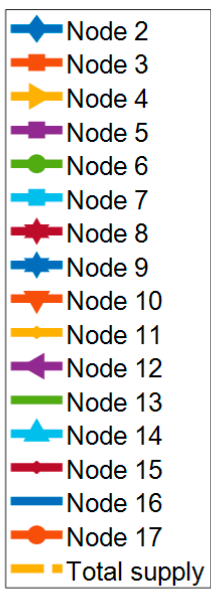

(h)

Figure 5. Results for different cost profiles/scenarios in Table A1, when the total electricity supply decreases by $10 \%$ per hour. The large graphs show the ratio of supply to demand for each node; small graphs—the corresponding cost profiles: (a) S14: cost profile is $[0.4,0.6]$; (b) S15: cost profile is $[0.2,0.8]$; (c) S22: cost profile is [0.4, 0.4, 0.2]; (d) S25: cost profile is [0.4, 0.2, 0.4]; (e) S32: cost profile is $[0.2,0.4,0.2,0.2]$; (f) S35: cost profile is $[0.2,0.2,0.3,0.3]$; (g) S41: cost profile is [0.2, 0.2, 0.2, 0.2, 0.2]; (h) The legend of all scenarios. 
In S32 scenario (Figure 5e), the electricity supply at most nodes drops initially by $20 \%$ of their demand because the first sub-cost is allocated to $20 \%$ of the total demand in the nodes. After that, the supply starts dropping to $40 \%$ once all nodes reach $80 \%$ of demand, since $40 \%$ of second sub-cost is allocated, and this lasts longer than the previous one due to the larger sub-cost $(40 \%>20 \%)$. Then, as the total electricity supply reduces continuously, the nodes start to drop to $20 \%$ one by one after all nodes reach $20 \%$ of their functions, assuming the third sub-cost is $20 \%$ of the total cost of unmet demand in each node. Then, all drop to $0 \%$ once all of them reach $20 \%$, according to the $20 \%$ of fourth cost (small figure in Figure 5e). It is noted that the length of sub-total cost profile (scale of horizontal axis in the sub-figure in Figure 5e) is proportional to the length of extra time that each node could gain, as indicated by the horizontal length of the large figure in Figure $5 \mathrm{e}$.

The step number of cost profiles could determine the reduction step of each node. For example, the two-stepwise profile makes the solution drop twice (Figure 5a,b) while the three-stepwise profiles cause the solution to reduce three times, gradually (Figure 5c,d). Then, the length to each step contributes to the length of extra hours in each node. For example, in S32 scenario shown in Figure 5e, the first 20\% sub-total cost could let the supply of each node reduce by $20 \%$ for $2 \mathrm{~h}$, as the production is assumed to reduce $10 \%$ each hour. Then, the second $40 \%$ sub-total cost contributes to an extra $4 \mathrm{~h}$ after they drop a further $40 \%$. After that, the further drop of $20 \%$ for $2 \mathrm{~h}$ is due to the next step (20\%), and the final drop to $0 \%$ is due to last step of $20 \%$.

While setting up the upper bounds of sub-total unmet demands, it is necessary to make these as percentages of the total upper bounds. For example, Xxub1 $=0.6$ Xxub; Xxub1 $=0.4 X x u b$. In this case, the model results may deviate from the solution of the case without subdividing the unmet demands where the results do not change. But if one only changes the upper bounds without considering the stepwise of sub-total unmet demands, the results are always the same as the original solution. Therefore, the constraints of the equation should introduce the percentage of maximum demands $k_{j}^{i}=\% k^{i}$. Therefore, by considering the stepwise of cost profile, the corresponding upper bounds should also be modified (Equations (8) and (9) are necessary).

By applying this model, it is possible to redistribute the commodity in the system network when the supply is partially interrupted. Keeping CI assets at nodes on minimum supply can improve the resilience of the town. For example, there is a sewage treatment plant connecting Node 15. If only one constant cost is employed for the unmet demand in this node, the sewage treatment plant cannot be functional, even if the total supply is not very low (Figure 4). However, if we consider this cost as a stepwise function, e.g., as shown in Figure 5e, then the plant could be kept functional for at least an extra hour before reducing electricity supplement of the connected node to $60 \%$, and extra 3 hours before reducing to $40 \%$. This could prevent the spillage of untreated sewage during the hazard, while not affecting the minimum electricity supply requirements of other critical infrastructure components such as hospitals or home cares. This is also the case for the sewage pumping station at Node 14, which indicates that the assumed stepwise cost of the unmet demand enables the pumping station to be in operation for a longer period.

In all scenarios in Table A1, due to the lack of specific data, it is assumed that all nodes follow the same cost profile shown in the small graphs. However, this can be changed according to the situation in each node, if needed. Additionally, the model can distinguish the steps only because of the 10th order difference between each sub-total step. This is similar to the process of making the entire system with several virtual layers ( 4 virtual layers for a 4-step cost profile); in each layer, the optimisation with one unmet demand coefficient is simulated before the final combination of all of these layers. 
The question is then how to build up the stepwise profile for each node, and whether these profiles are interdependent. If it is connected to flood conditions, it can be assumed that the probability of failure of a specific infrastructure asset (e.g., electricity substation) is proportional to the flood depth at the location of this asset. Additionally, the rate of the supply reduction may also be related to the pace of the evolution of the hazard itself: flooding to a specific depth at the location of an infrastructure facility can interrupt its functioning partially or fully. The geographic connection with a flood model is a promising method. Puno et al. [16] used a GIS spatial technique to connect the flood risk with a hydraulic flood model. Therefore, we introduce a numerical flood model next to consider the probability of failure for each node based on a temporal-spatial distribution of flooding conditions. This type of a system-modelling approach is applicable to other infrastructure systems as long as a proper connection between the two models is established.

\subsection{The Flood Model}

In order to apply the above-improved network model into a real hazard, we further introduced a flood model to estimate the flood probabilities of CIs in the selected small town (Figure 1) under flooding hazards. As the flooding model requires a specific geo-location, we needed a real case study to apply the above concept. Although the above schematic network reduces its connections, the geographic location for each node is identical to the real case, which is still able to represent the real situation. The flooding results could provide insights of the flooding probability of each infrastructure asset and flood distribution map, as well for the town development/planning in the local community. The sustainable town planning could also be guided by these flooding model results, considering the future climate change in a long-term aspect. The flood model adopted here is LISFLOOD-FP.

LISFLOOD-FP is a 2D hydraulic model that is capable of predicting the time evolution of water depths (inundation) over fluvial, coastal, and estuarine floodplains using limited CPUs [8,9]. LISFLOOD-FP is an open source code and has been widely applied in flooding studies based on Digital Elevation Model (DEM) topography, which could consider coastal inundation, river flooding, or compound flooding. It could predict the flood inundations by the $2 \mathrm{D}$ finite difference method on raster-based grids, provided that the proper boundary conditions are prescribed. The flood maps could be obtained by inputting the time series of river discharges or water depths from upper streams and down streams, which are associated with tunable model parameters such as time steps.

Thus, this reduced-physical model has high computational efficiency suitable for Monte Carlo simulations with thousands of scenarios. In addition, the network flow and flood models are coupled statistically, which do not require a fully-resolved physical flood model at the cost of computational time. Therefore, it is unnecessary to setup complicated flood models, such as the catchment-based flooding model considered in drainage systems $[17,18]$, for the purpose of this study. The model setup in this study could be referred in Figure A1.

In this paper, we examined the influence of future climate change based on the green house medium emission scenario (A1B projections), which assumes that the reliance on all energy resources is balanced between fossil and non-fossil energy sections under the rapid economic/technology growth storyline in the future [19]. One of the components from climate change is sea level rise (SLR), which can affect most coastal processes such as waves, tidal propagations, storm surge levels, wave overtopping, and their couplings [20]. Consequently, the risk to coastal communities from the coastal flooding could increase. It is essential to implement the compound flooding for the investigation of coastal resilience, as the combination of coastal and river flooding could increase the risk for low-lying areas further under sea level rise [21,22]. In this study, we added a sea level rise of $1 \mathrm{~m}$ for the medium emission scenarios at the coast of the study site for the extreme water level of return periods. More details will be discussed in the following section. The comparisons of the flooding probabilities at infrastructure assets between present and future scenarios in a changing climate were taken into account before applying them to the network infras- 
tructure model, to see whether the CIs will be at risk in the future climate. The results are valuable to assess the risk and resilience of the entire infrastructure system network in the town, considering the interdependencies of each sub-system. By incorporating the flooding model results in the network model of CIs, it is also possible to assess the cascading effects for different infrastructure sectors (i.e., electricity, water, sewage) in this area to provide insights into improving the resilience of the entire town to flood hazards and climate change. This has been discussed by Val et al. [5], but they use assumed probabilities of flooding rather than the ones obtained from a flood model.

\subsubsection{Model Setup}

Historically, the selected small town has experienced approximately 40 flood incidents from 1956 to 2012 (data from local government), among which river flooding comprise the majority, while there are also surface runoff and coastal flooding at the small harbour, cottage, and back dune areas (personal communication from town governor). Therefore, the town could be at risk of flooding although it is not severe in most areas. However, some critical infrastructures were flooded historically (i.e., the central electronic station, shown in Figure 1).

We applied the reduced-physics hydraulic model LISFLOOD-FP here in the interested area by considering various flooding scenarios. The model was first calibrated and validated with the SEPA flood map containing a range of return periods (data not available due to confidential issues), forced by extreme river discharges in the corresponding return periods derived from the observed river gauge data at the upstream of the river across the town (the south boundary of shaded area in Figure 1). The extreme value analysis was applied first to the historical river gauge dataset, to obtain the extreme boundary conditions for the hydraulic model via regression analysis. Then, the parameters, such as grid size, time steps, and roughness, based on the land cover characteristics shown in Figure 6 were tuned during the calibration process. After this, the model with setup parameters that could at least reproduce the flood extensions of the SEPA flood maps was applied in Monte Carlo simulation. The detailed processes are discussed in the following section.

In this study, we de-refined and interpolated the $2 \mathrm{~m}$-LiDAR DTM (Digital Terrain Models that removes earth surface structures) from the Scottish Government data archive to the model domain with a grid resolution of $20 \mathrm{~m}$ based on raster DEM, to reduce the computational time. By tuning the spatial distribution of roughness, which was derived from the Land Cover map (based on Manning material categories), the final spatial distribution of roughness was determined (Figure 6) [23]. The land use is important for flood risk analysis [24], particularly when considering the flood risk under climate change in long term periods, as the features of land could sometimes determine their vulnerability. However, here we assumed the land use remains the same as in our climate scenarios, also without considering the morphological change on the beach and the future land planning due to lack of data. In addition, the earth surface buildings and vegetations are excluded from this DEM based model. The major task was to prepare the two open boundaries for both river and sea sides. 


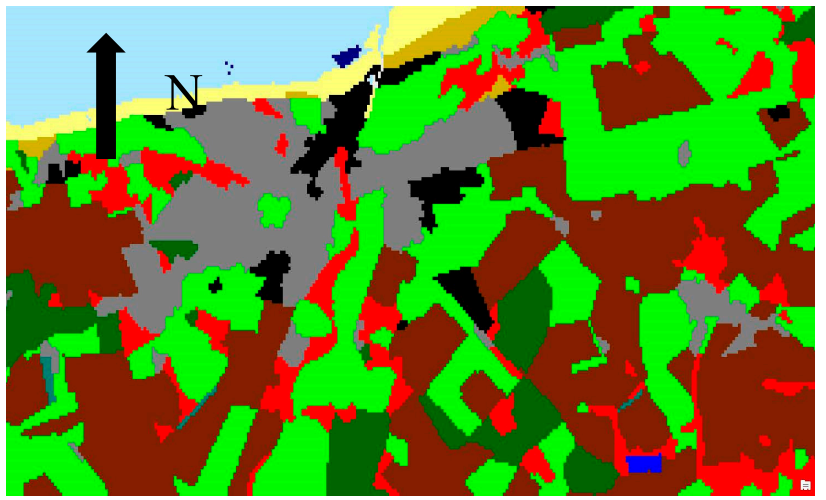

(a)

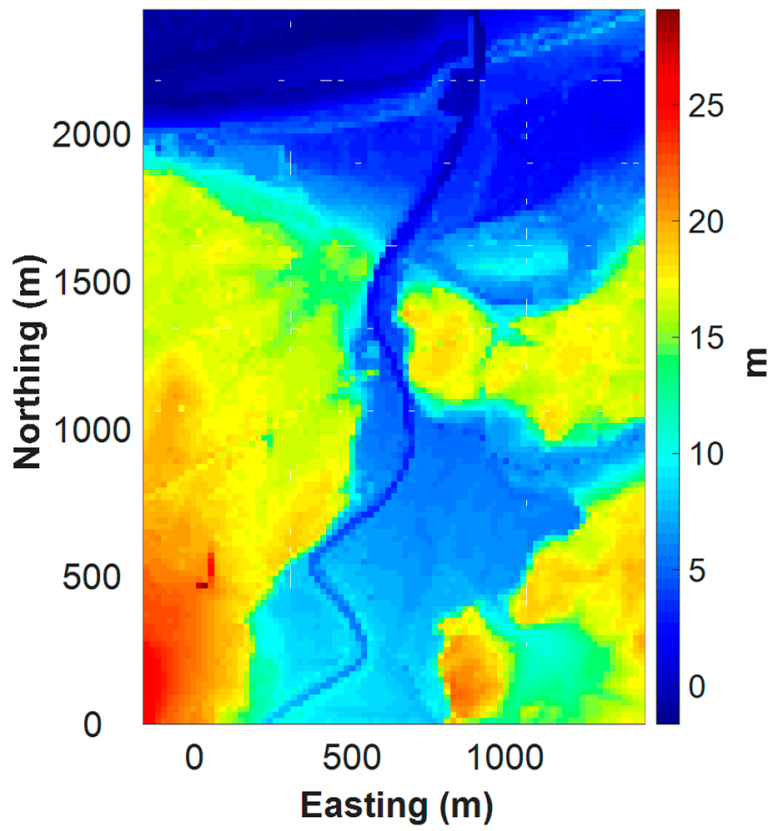

(c)

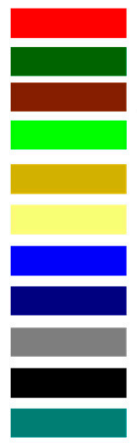

Broadleaved Woodland

Coniferous Woodland

Arable and Horticulture

Improved Grassland

Supra-littoral Sediment

Littoral Sediment

Freshwater

Saltwater

Suburban

Urban

Bog

(b)

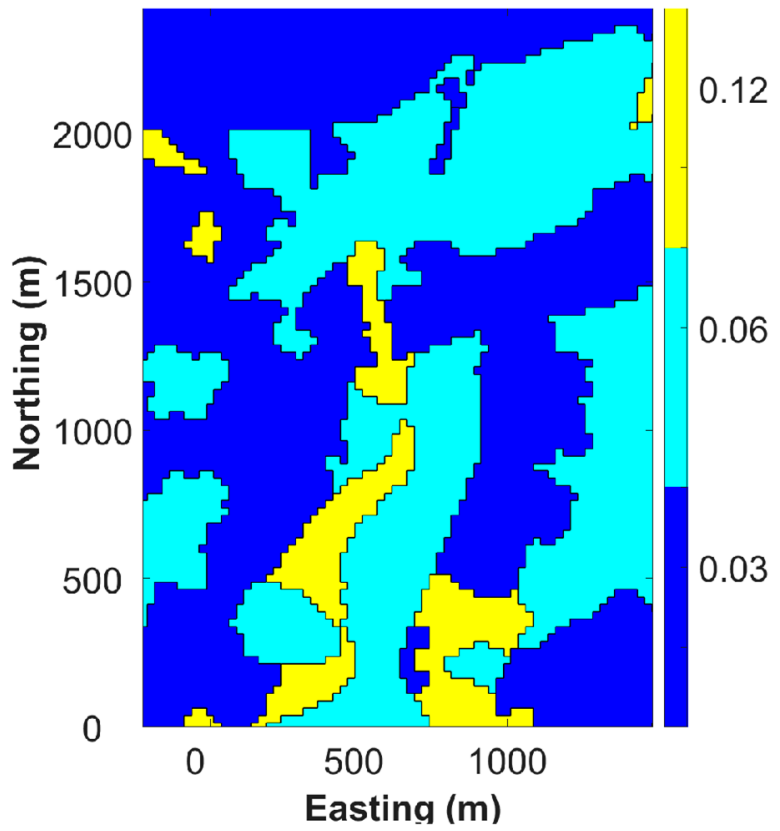

(d)

Figure 6. The flooding model setup: (a) Land Cover of the interested area [23] (C) NERC (CEH) 2017. (c) Crown Copyright 2007. Ordnance Survey License); (b) the legend of the land cover; (c) the DTM data with $2 \mathrm{~m}$ resolution (source: Scottish Government data archive (c) Open Government License); (d) the final, tuned roughness of the flood plain based on the land cover at the (a), with a de-refined $20 \mathrm{~m}$ resolution. The north and south boundary of the domain is seaside and river side, respectively, where the boundary conditions vary in various scenarios. The coordinate system is offset from the original dataset but keeping the scale and distance for confidentiality issues.

\subsubsection{Model Boundary Conditions}

For the river side boundaries, since we have river gauge data that covers the period from 1989 to 2019 with 15 minutes resolution; we applied the extreme analysis to get the return period values. The annual maximum values were extracted from this dataset, and we fit them into a general extreme value (GEV) distribution (Figure 7). Then, three return periods of water discharge from the river gauge data were obtained for the validation scenarios (1 in 10-high likelihood, 1 in 200-medium likelihood, 1 in 1000-low likelihood). To generate the discharge profile from river gauge data for daily conditions: we first found the storms (discharges) that were larger than threshold in the $15 \mathrm{~min}$ interval dataset to get discharge profiles; it was assumed that if the interval between two storms is less than $1 \mathrm{~h}$, we make them as one storm; the number of storms and their durations were obtained. Here, we picked up a specific storm profile to apply in our study, but normally the storm 
duration and peak value of storms can be based on joint probability. Then, we scaled the profiles with different return period values and generated extreme flood events with the same storm duration (each peak discharge is corresponding to the values of different return period values above). Then, we applied the new scaled profile into the hydraulic model for validation simulation.

Probability Plot

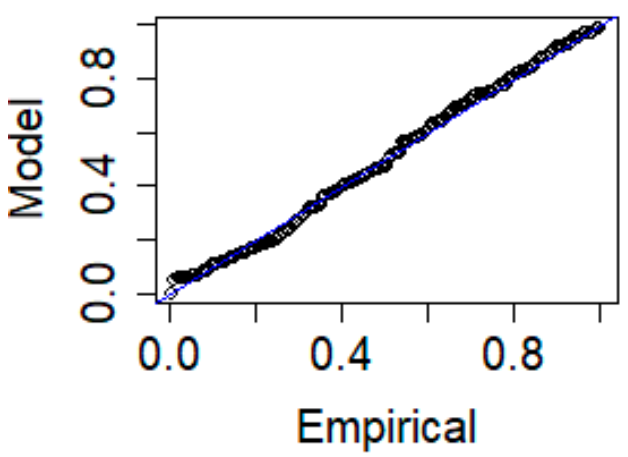

Return Level Plot

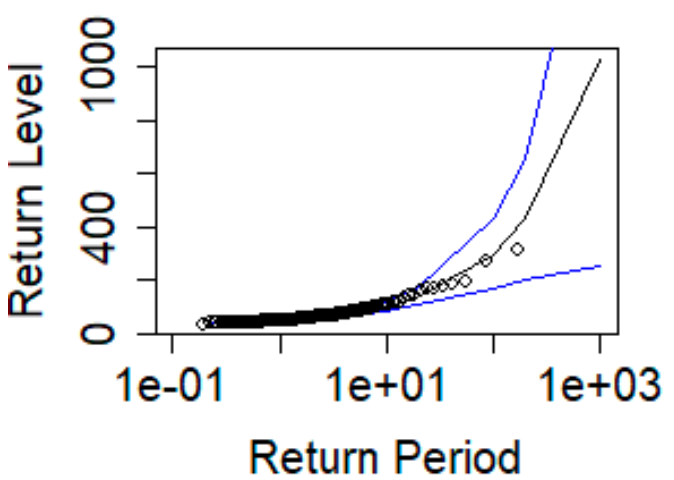

Quantile Plot

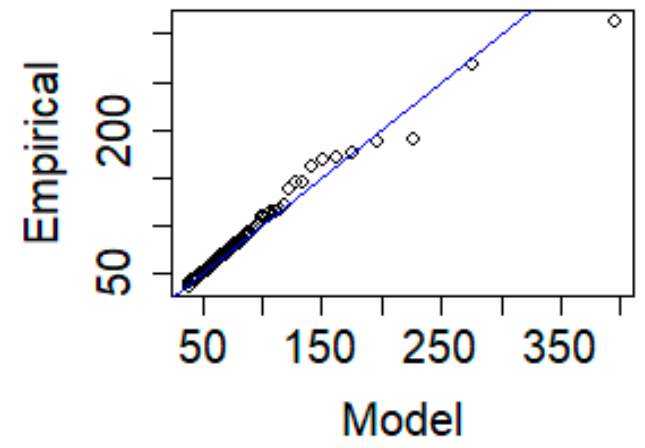

Density Plot

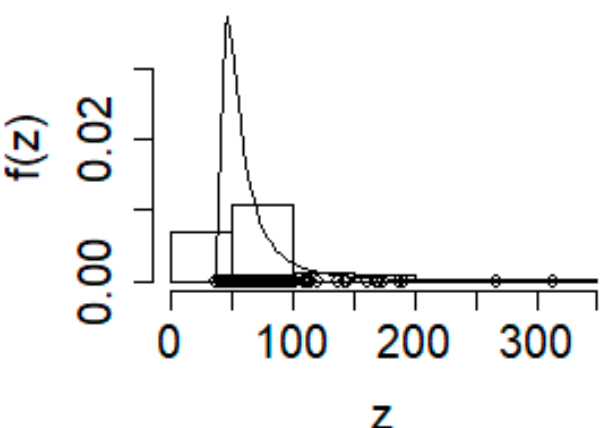

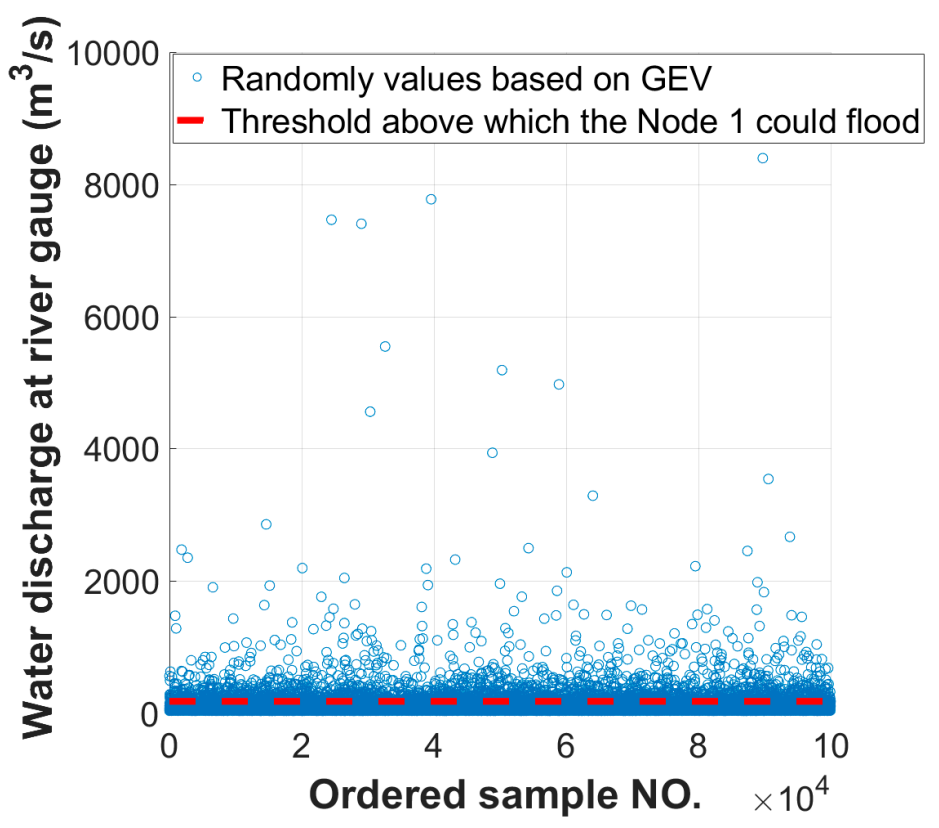

Figure 7. GEV diagonal fitting for annual maximum river gauge data and the return periods of water discharges at the river gauge. Bottom: the peak flood values are selected for the present scenarios. 
For the seaside open boundaries, we combined the mean high water springs (MHWS, shift from Newlyn Ordnance to mean sea level) with different return periods of extreme water levels derived from McMillan et al. [25], which was also applied by Yin et al. [26]. The extreme water level is based on the skew surge joint probability method (SSJPM) analysis of tide-level data recorded at 40 Class A gauge sites (the periods of these sites vary between 10 years to 100 years). Since the sites are sparse across the whole UK coastline, they applied 40-year coastal modelling data, forced by ECMWF ERA40 meteorological reanalysis, to aid the gauge data analysis for obtaining extreme water levels for approximately every $2 \mathrm{~km}$ distance across the whole UK coastline. More details are referred to in McMillan et al. [25]. We selected the extreme water levels from the site closest to our study area as an input of coastal boundaries for our flooding model. It was assumed that the water level at the coastal boundary remains constant over time.

\subsubsection{Model Validations}

Then, based on the above boundary conditions, three extreme scenarios were simulated for the validation and compared with the SEPA flood map (only for the extension). The validation index is based on methodology in Schumann et al. [27]. $F=A /(A+B+C)$; $\mathrm{A}$-the areas correctly predicted as flooded; $\mathrm{B}$ - the areas where the flood extent is overpredicted; $\mathrm{C}$ - the under- predicted flood areas. $\mathrm{F}=1$ is a perfect prediction by a hydraulic model. Herein, the $\mathrm{F}$ value is around $52 \%$, which is reasonable due to the digitised SEPA flood map. Also, the SEPA flood map considers the coastal flooding and river flooding separately, without considering their interaction. Therefore, by assuming a constant high water level, the current flooding model could overestimate the flood depth when compared to the SEPA flood map.

\subsubsection{Monte Carlo Simulations}

Next, we applied the validated flood model for the small town with numerous extreme scenarios for both present and future conditions in order to generate enough numbers of flooded depth values in each infrastructure asset. The assumed flood events at the upstream boundary were generated by scaling the derived extreme values the random values obtained from fitted distribution with flood profile (generated from observed data) (Figure 7). With the input of these events in the hydraulic model, the corresponding Monte Carlo simulation outputs of flooded depths in each infrastructure assets can be obtained, as well as the spatial distributions of flood depths in each event. After that, the probability of each infrastructure asset can be obtained so that it could provide the estimation of failure possibility or operational possibility of each infrastructure asset.

For the present scenarios, the upstream boundary conditions were scaled, extreme values from the Monte Carlo random simulations that were generated from specific GEV distributions with the same storm profile (i.e., same storm duration), based on the assumption that storm profiles are identical. By getting thousands of values for peak floods from the specific GEV distribution (Figure 7), we could input them into the flood model for Monte Carlo simulation runs, for thousands of flood scenarios, where we assumed the coastal boundaries are constant in water level (extreme water level for 1 in 100 return period).

For the future scenarios, the upstream river discharges followed the same method but were derived from different datasets: the predicted catchment data from CEH 'Future flows and Groundwater Levels' project [23], which covers 1951-2098. By extracting 40 years of data (2058-2098), we followed the same procedure as present scenarios and obtained thousands of values for each node, as well through Monte Carlo simulations, after the bias correction of CEH data (1989-2019), based on observational data the river gauge. For the coastal boundaries of future scenarios, we considered only one sea level rise (SLR) scenario under medium RCP scenarios [19], based on the present extreme water conditions. Here we just added $1 \mathrm{~m}$ SLR at the coastal open boundaries. Then, by adding both open boundaries into the flood model, we could run different flooding scenarios (1318 scenarios) 
for the future conditions by using Monte Carlo simulations. The aforementioned procedure is described in the flow chart in Figure 8.

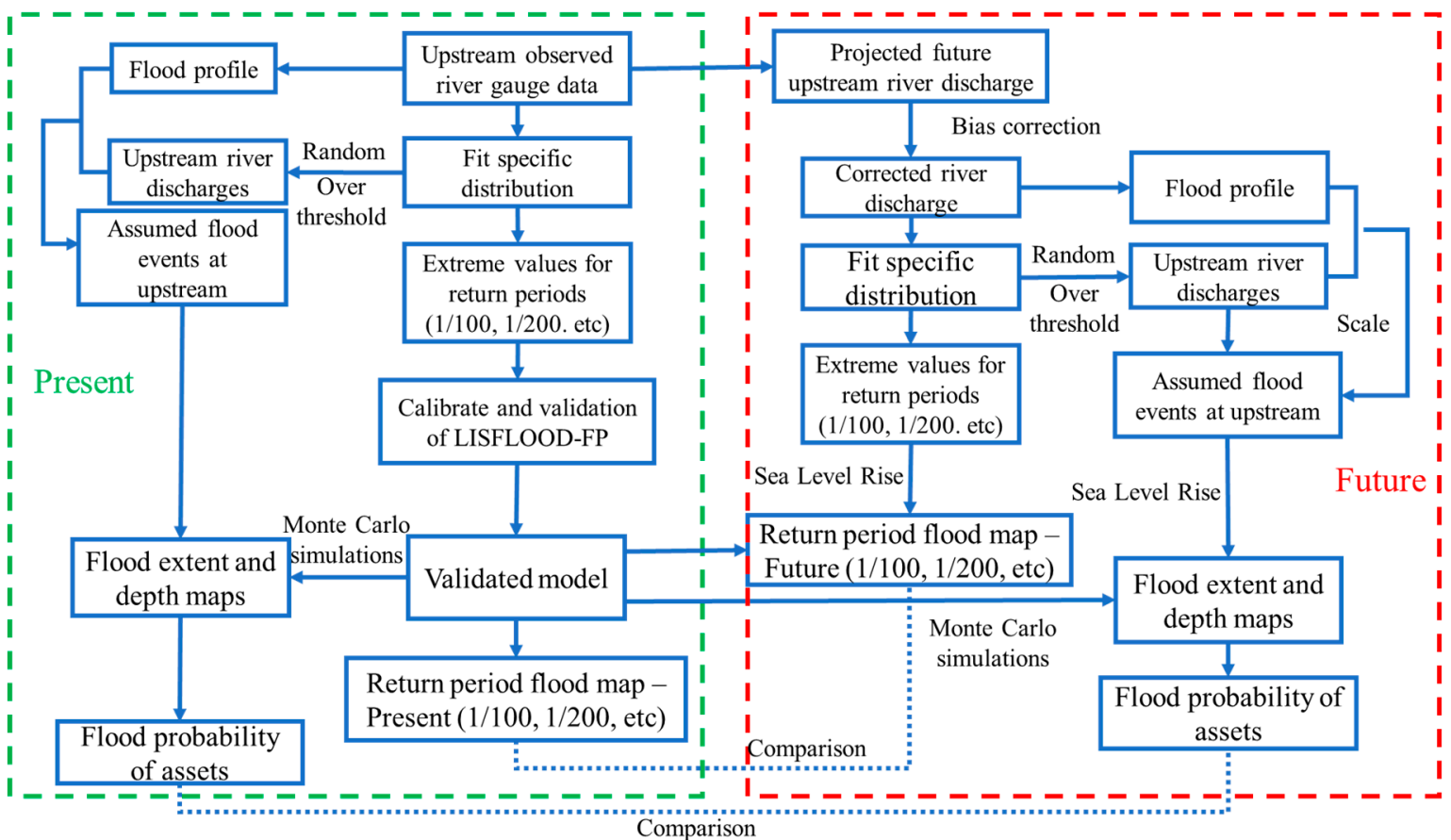

Figure 8. The flow chart of hydraulic modelling in the small town case to consider both present (green) and future (red) scenarios with sea level rises and climate change.

\subsection{Combine Flood Model and Infrastructure Network Model}

Finally, based on the above flooding Monte Carlo scenarios, the corresponding outputs of the inundated depths in each infrastructure asset, as well as the spatial distributions of flood depths could be obtained for each event. We then created sufficient scenarios for the probability analysis of flooding for each infrastructure asset, based on the variation of different flooding depths. For those nodes that were never be flooded, the flooding depth would be 0 . If the zeros in each node exceeded $2 / 3$ of the total number, it was assumed this node has no chance $(0 \%)$ of flooding and it will $100 \%$ operate normally under the flood event. Then, the final probability inputs described above could be implemented into our infrastructure model to derive the probability of each node of operation and their connections between each other. Additionally, the cascading effects of the hazard on the final network system could be examined statistically based on the real flooding scenarios and all data collected above.

\section{Results and Discussion}

The two numerical models can provide different information for this case study, as the cascading infrastructure interruption depends on the hazard itself.

\subsection{Flood Model Results}

For the specific return period scenarios, the flooding in each return period became less significant in the future for the entire town even under the sea level rise scenario. However, in the coastal area, the coastal flood in the future might become more severe and frequent due to the sea level rises (SLR). For the town overall, the increased coastal flooding due to SLR might not make up for the reduced river discharge in the future, since flooding is mainly due to the river flooding. However, more sea water could inundate into the coastal inland where important infrastructures are located, such as a large caravan park (partially included in the hydraulic model), which was also recorded as a flood event historically 
(personal communication). Three main areas are most vulnerable to flooding: the coastal area around a street near the river mouth (west of the river); the coastal area at the Holiday Park (east of the river); the entire part of a farm (around Node 6 in Figure 3) on both sides of the river. It is also illustrated that the increase in the flood probability will not enlarge the flood extension too much, but will mainly increase the flood depths at the vulnerable areas. This means that the infrastructure assets, which are located in current safe places, might still be safe from flooding in the future. This might be related to droughts in some areas of the UK being potentially increased [28].

The comparison of the exceedance probabilities of flood at each infrastructure asset location in the town indicates that these probabilities will decline in the future for almost all asset locations. This might be because the drought of the river becomes more probable under the considered future climate scenario. For specific flood depths, the probability of exceedance (reverse of non-exceedance, cumulative distribution function-CDF, shown in Figure A1) becomes smaller in the future, which means the probability of failure of infrastructure assets due to flooding will decrease as well. For example, in Figure 9, the probability of flood depth at Node 1 that is less than $2 \mathrm{~m}$ is around $70 \%$ in the present $(\mathrm{CDF}=\mathrm{P}(\mathrm{x}<2)=0.7)$, while this value may increase to $90 \%(\mathrm{CDF}=\mathrm{P}(\mathrm{x}<2)$ $=0.9)$, which means the probability for the flood depth to exceed $2 \mathrm{~m}$ at Node 1 is $30 \%$ $(\mathrm{P}(\mathrm{x} \geq 2)=1-0.7=30 \%)$ in the present and $10 \%$ in the future climate. For the electricity system, three electricity transformers are currently at risk of flooding and the probability of that can change in the future. The first is the central transformer (Node 1, red dot in Figure 9); the second is Node 6 (magenta dot in Figure 9); the third is the electricity transformer at Node 14 (white dot in Figure 9). The changes in the probability of flooding of these three assets can be seen in Figure 9, which shows that the CDF will increase in the future, meaning that the probability of failure due to flooding will decrease. In the sewage system, most assets, including the sewage treatment plant, are located at the mouth of the river, and the probability of their flooding will decrease in the future based on the river flooding model predictions.

Most of these sewage system facilities are located at the west side of the river and experience a similar trend with that in the electricity sector: an increase in the CDF of flooding depths at each site and, subsequently, a decrease in the probability of failure of each facility (Figure 10). However, it is not just these facilities themselves that are under the flood risk, their power supply might also be at risk. For example, the electricity to the sewage pumping station No. 2 in Figure 10 is supplied by Node 14 in Figure 3, which is one of the vulnerable electricity transformers mentioned above. In this case, the cascading effects from failure of Node 14 will also be felt by the connected sewage pumping stations. Regarding the town's water system, its operation is based on gravity rather than using a water pumping station. This reduced the risk to the water system from cascading effects of the electricity network failure. Thus, the water system should not be greatly affected by flooding. Other facilities such as a hospital, care homes, and a railway station, are not flooded in even the most serious flood conditions. However, it should be noted that to assess the flood risk for each asset is quite difficult, as the latter would depend on three main factors: hazard, exposure, and vulnerability. Here we are only looking at the flood hazard, without considering the land use, which could be important for the flood risk assessment [24]. 


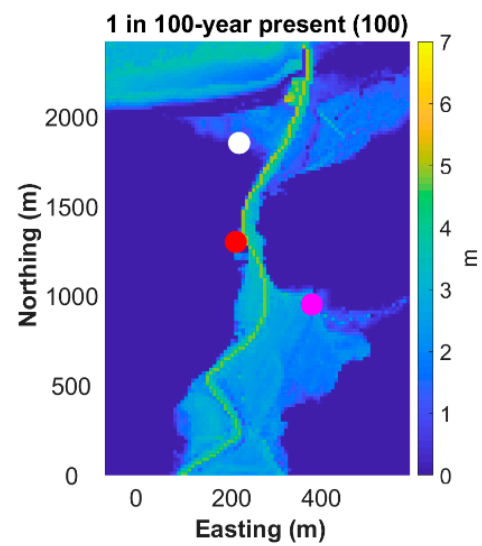

(a)

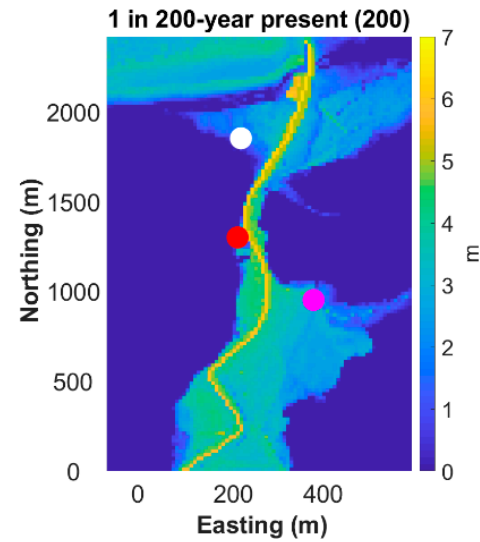

(d)

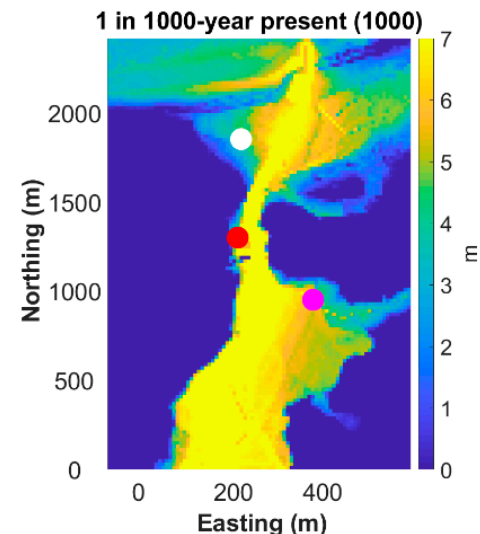

(g)

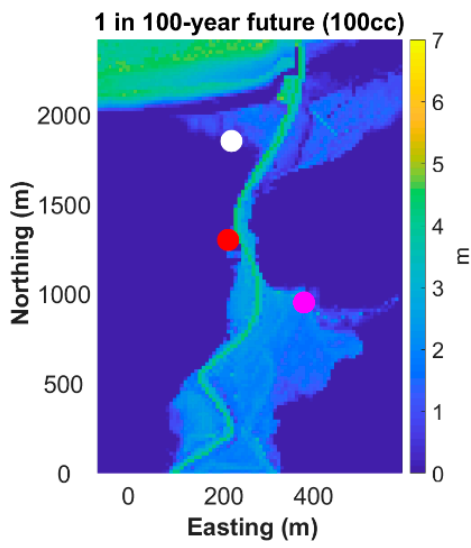

(b)

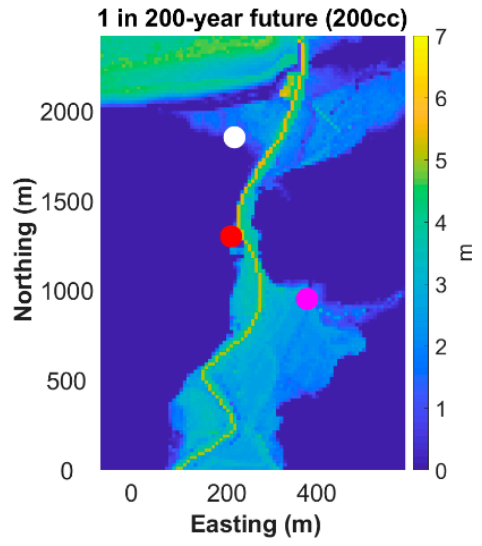

(e)

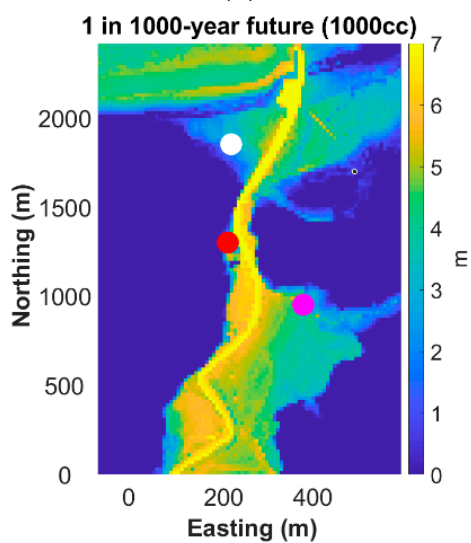

(h)

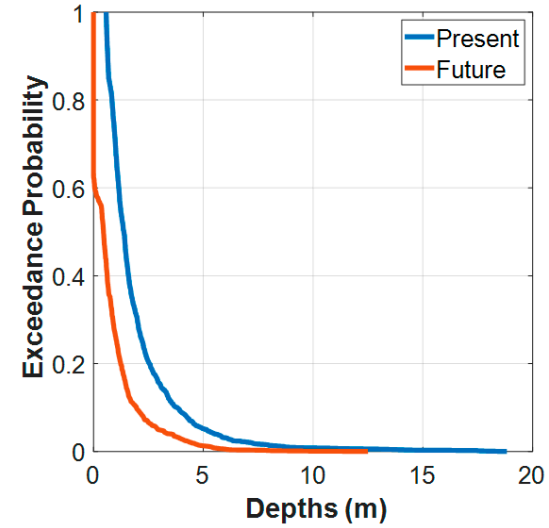

(c)

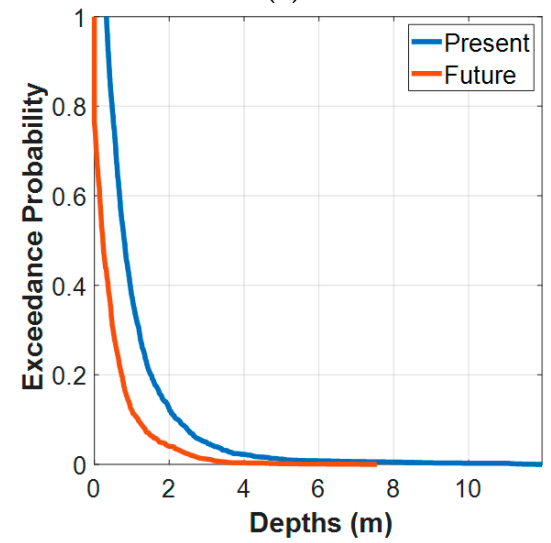

(f)

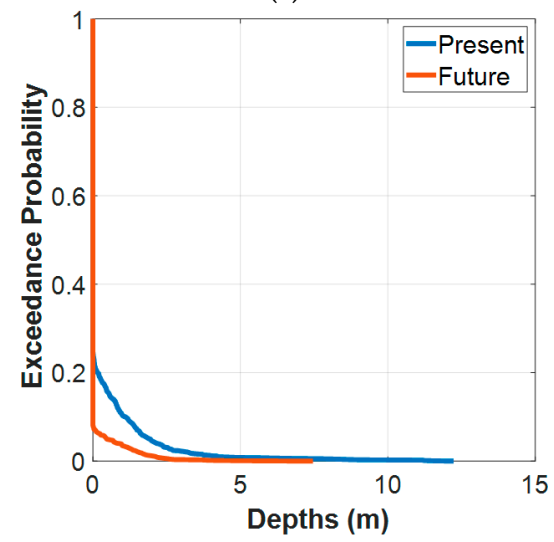

(i)

Figure 9. The flood of three different return period scenarios under present conditions: (a) 1 in 100 return period; (d) 1 in 200 return period; (g) 1 in 1000 return period and under future scenarios with climate change (CC): (b) 1 in 100 return period; (e) 1 in 200 return period; (h) 1 in 1000 return period. The main electricity transformers Node 1, Node 6, and Node 14 are marked as red, magenta, and white solid circles, respectively) and the exceedance of probabilistic distribution of flooded depths at these three most vulnerable electricity transformers (Nodes): (c) Node 1; (f) Node 6; (i) Node 14. 


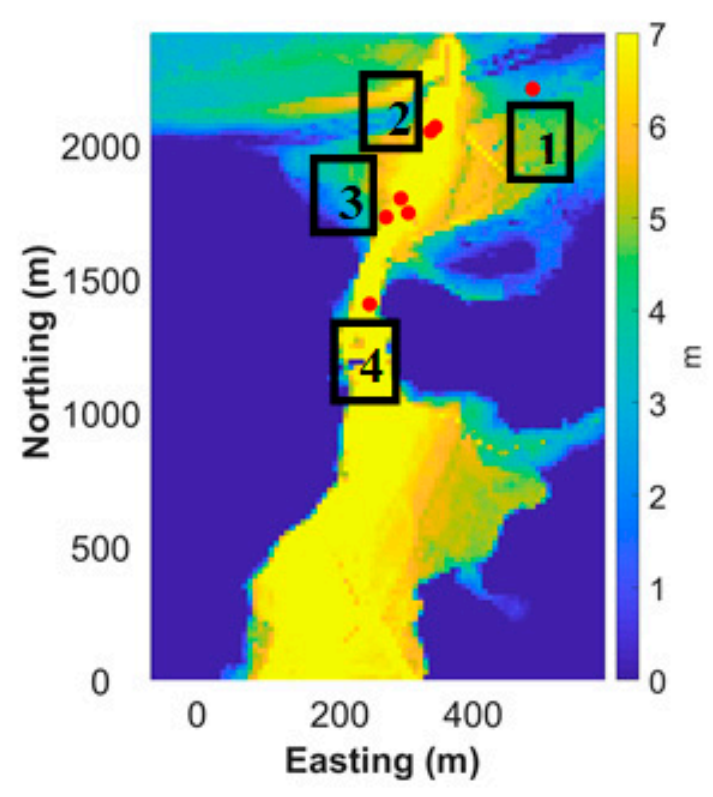

(a)

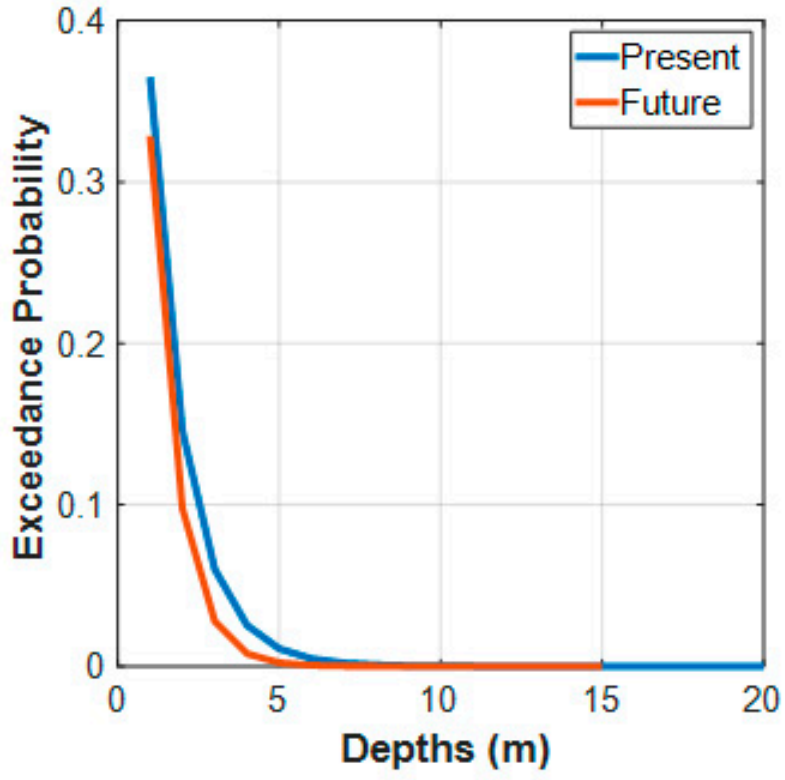

(b)

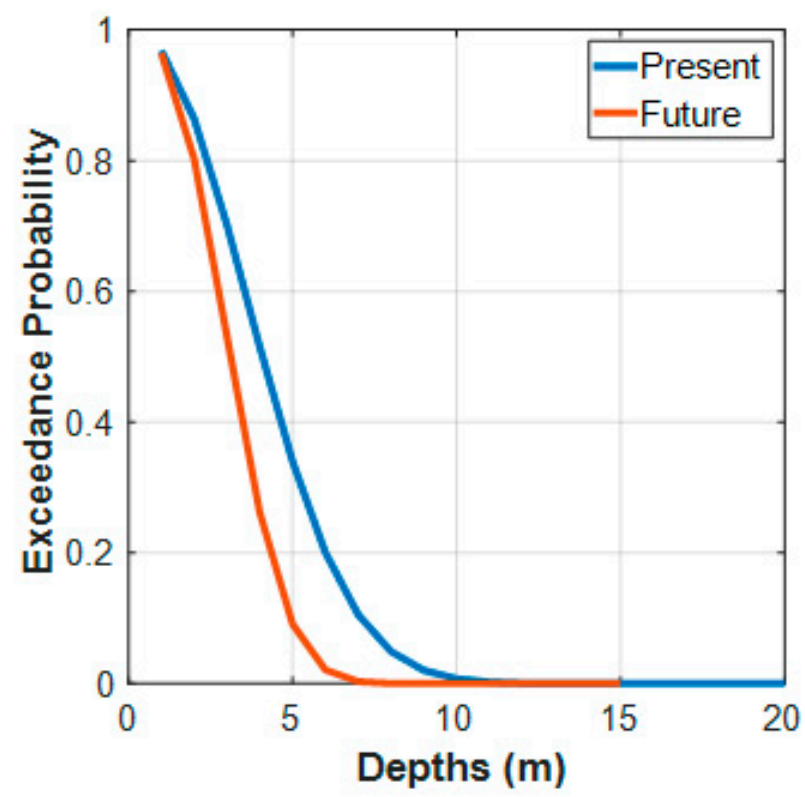

(c)

Figure 10. Cont. 


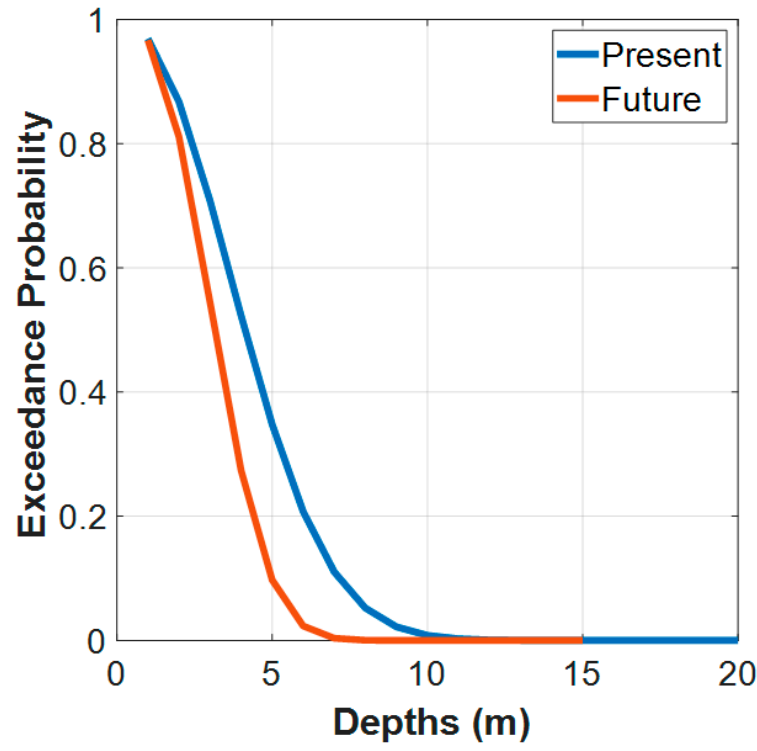

(d)

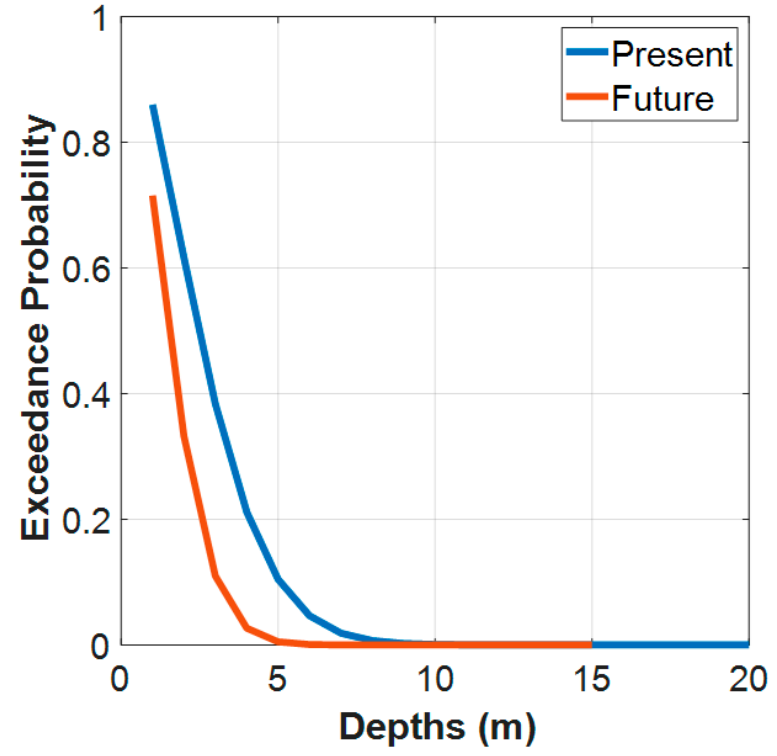

(e)

Figure 10. (a) Locations of sewage stations marked in red dots and the representative sewage pumping stations are marked in rectangular and the exceedance probabilistic distribution of the flooded depths at each representative pumping station: (b) station 1; (c) station 2; (d) station 3; (e) station 4. It is assumed to use one station if they are closed to each other; here there are a total of 4 representative sewage pumping stations: marked as pump 1 to pump 4 from top to bottom, shown in (a).

The infrastructures are physically interdependent, which means the cascading effect cannot be ignored, even though the infrastructure assets are not at risk of flooding. Even though the probability of exceedance of inundation depths in the future may reduce, this does not mean that the entire infrastructure system will be much safer.

Uncertainties associated with the prediction of the future flood conditions are significant, since the present study only considers the medium emission scenario A1B, while other climate scenarios are also possible. Although it is expected that the river flood conditions will not change that much in the future at the considered location, the coastal flooding may be amplified significantly due to the sea level rise (SLR) (with one RCP scenario). It is also believed that when considering the storm surges at the seaside, including overtopping, the coastal area of the town under consideration will become more susceptible to flooding due to the interaction between SLR, storm surges, tide, and waves [29-31]. The coastal flooding risk may be mitigated by introducing coastal protection structures along the coastline, such as breakwaters and dunes, especially in front of the beach. For the sewage stations, as they are mostly located in the vulnerable areas, the protection from flooding will remain a challenge in the future, but the risk can be mitigated by back-up extra connections from safe electricity transformers.

Next, we input the probabilities of inundation depths from the flood model results into the multiple layers network infrastructure model. The final network model results driven by the flood depths were then used to assess the infrastructure failure probabilities.

\subsection{Coupled Hydraulic and Infrastructure Model Results}

Based on the results from the hydraulic model above, three main nodes are at risk of flooding: Node 1, Node 6, and Node 14, with the corresponding exceedance probability shown in Figure 9. As for the CIs, the possibility of operation for each substation could be described by a function of the flood depths [5]. Thus, based on the Monte Carlo simulation from the above flooding model, we could derive the probability of function for every specific node in the system, as well as for the sewage nodes (Figure 10). This determines 
the demands of electricity for each node which is based on the probability of floods at that node. The cost profile for each node is based on the critical system that covers the areas. For example, if the sewage pumping station connected to Node 14 is one important asset that is required to maintain the operation, then we need to set the supply percentage of this pumping station as the first priority layer (e.g., $20 \%$ of Node 14 demand is consumed by this station).

The final results with the implementation of the flood model inputs are shown in Figure 11, based on the assumption that the unmet demand cost profiles are stepwise. The two-layer cost profiles are only used for the three nodes that contain sewage network facilities (Node 7, Node 14, and Node 15). For those nodes that would never be flooded, they should be set up based on the commodity consumption proportions, which would be correlated to the flood extent covering the corresponding community. However, we only assumed that it is fully operated if the nodes have no chance to be flooded, as we cannot know the exact boundaries of each community for each node. The order between different costs stepwise could be ten, although this is based on the length of entire system, so that we could have enough distance for each stepwise, thus making the multiple layers completely separated.

Based on the data, different sewage network components are connected to various electricity substations (Figure 10): SW1 is connected to Node 15; SW2 and SW3 - to Node 14; SW4-to Node 7 (the node numbers are shown in Figure 3). These representative sewage stations follow the same assumption that the probabilities of themselves are a function of flooding depth, above which the function is interrupted. We assumed here that each sewage system is the first priority of the connected node, based on which we could determine the cost profile. The electricity demand of each sewage pumping station was used to set up the percentage of the unmet demand cost profile based on an assumption due to lack of data. We assumed that all three nodes have the cost profile based on [0.8, 0.2] sub-total unmet demand bounds.

Based on the probability profile derived from Monte Carlo simulations of the flood model, the final cost profile was assumed to be stepwise, with four layers (shown in Figure 11). The reduction of the production in the system is based on the stepwise flood probability predictions by the flood model. Then, the results indicate that once the flooding starts, all the CIs' nodes will be interrupted, but they could maintain the minimum demands for basic operation. However, as the exceedance probability profile become steeper in the future, the cascading results show the node could drop its function dramatically, which means the supply of commodity might be not sufficient, assuming that basic demands are not changed in the future. Therefore, even if the flooding might not become severe under the future climate conditions, the cascading effects could cause some nodes fail to be supplied with sufficient commodity, which is required for the future planning for the town under future climate conditions (Figure 11). However, more detailed future climate scenarios are required for further investigation, which could be a future work.

For the sewage system, the failure from flooding and cascading could play different roles. For example, it is noted that in Figure 10, SW1 could be less at risk than SW4 from the flooding, as SW4 is close to the river. This means that if we consider its function only from flooding scenarios, the SW1 might be much safer than SW4. However, when including them into the cascading network, it was found the SW1 would be firstly interrupted in the basic network solution in which there is no sub-total cost profile setups, because its connected Node 15 would be first interrupted. 


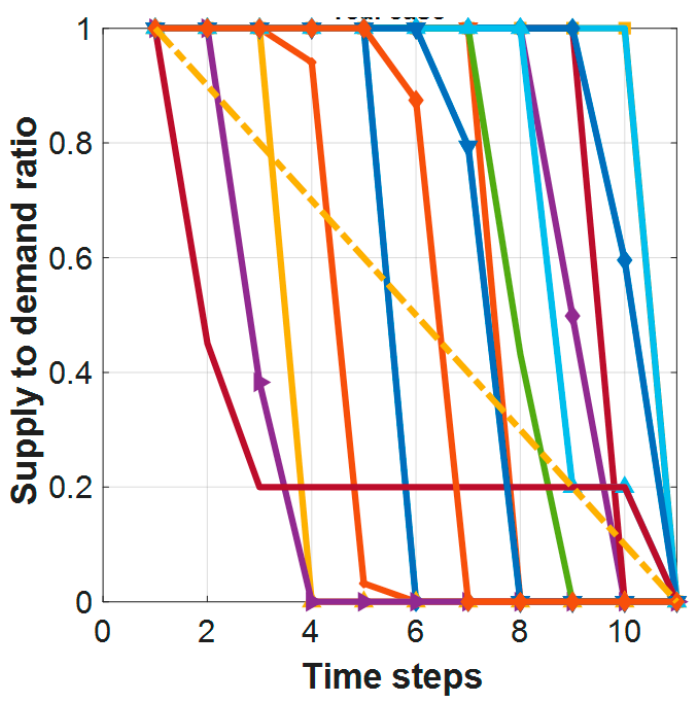

(a)

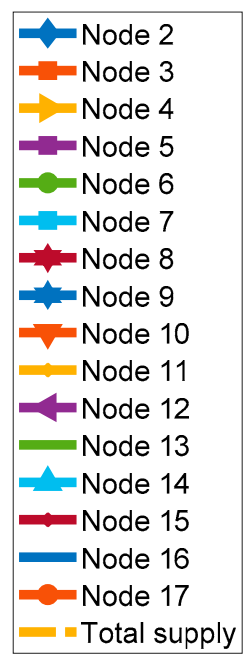

(b)

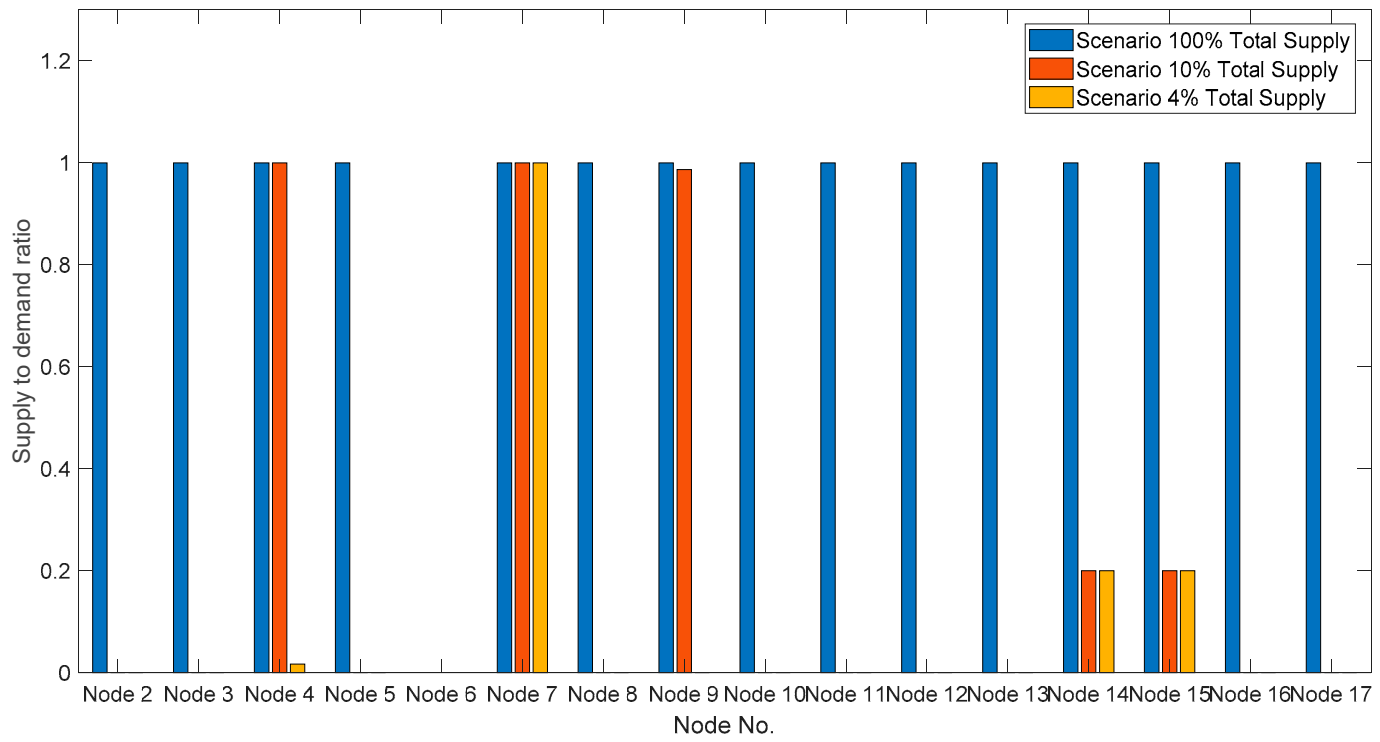

(c)

Figure 11. The final results that are based on an assumption of probability profile from the flood model and assumed cost profile. Here, we assumed the cost profile is stepwise only for Node 7, Node 14, and Node 15, and the three vulnerable flooding nodes (Node 1, Node 6, and Node 14). (a) Resulted scenario, considering the cost profile for the three nodes without any flooding probability included with reducing the supply 10\% gradually; (b) the legend of lines in (a); (c) Scenarios considering both flooding and stepwise cost profiles with reducing of supply based on the flood model results; the supply/demand ratio value with 0 did not show in the bar.

By considering the sub-total cost profile, the results also show that even though Node 15 could interrupt first, it is still able to provide the electricity for the sewage treatment plant (SW1) for extra hours, while other consumptions are crashed. For SW2 and SW3, which connect to Node 14 that disrupts later on, this could also last for several hours before the supply to Node 14 is totally shorted. For SW4, even in the solution of no sub-total scenarios, it could maintain the operation for a longer time. Thus, this sewage pumping station would be the safest when only the cascading effects related to electricity supply are considered. 
Therefore, based on above discussion, we could not use the flood model alone to determine the state of the sewage system since its operation is strongly dependent on other commodities, i.e., electricity supply. The combination of the flood model and the infrastructure network model provides us with a better method for studying the coastal communities' resilience and helps to identify important issues that could not be detected from either flood or network modelling individually.

\section{Conclusions}

In this paper, we have presented the combination of an extended network flow model and a flood model, which can be used for the assessment of the vulnerability of small and medium-size communities, which are at risk of flooding (both river and coastal). The network flow model is a further extension of the model described in Val et al. [5]. The latter has been improved so that it can be applied to the analysis of interdependent infrastructure systems, which contain loops, while the direction of the commodity flow in the loops can be changed throughout the analysis. It has also been shown that the previous network flow model formulation does not allow us to properly control the distribution of commodities between consumer nodes in unbalanced networks (i.e., when the available total supply of a commodity is less than its total demand). To resolve this issue, we have divided the unmet demands in consumer nodes into sub-totals and described the costs of the sub-totals by a stepwise function. A formulation of the optimisation problem for solving unbalanced networks with stepwise costs of unmet demands has been presented and then illustrated, using an electricity network in a small coastal town as a case study. It is proven that the newly improved network model could be capable in redistribution of commodities even in a bi-directional infrastructure system.

Using the same case study, we have demonstrated how the reduced-physics hydraulic model LISFLOOD-FP can be used in combination with Monte Carlo simulations to estimate the probabilities of inundation depths at different locations for various flood events. The impact of climate change on such probabilities has been taken into account by considering SLR and future projected river discharges from the flood model. Finally, we have used the calculated probabilities of inundation depths to assess the risk posed by flooding to the CIs - electricity and sewage systems - of the town considered in the case study. It has been shown that applying the network flow model and the flood model separately cannot correctly identify all risk to the CIs, especially the sewage system, due to flooding. It therefore required a coupled model system to consider the resilience of coastal communities from natural hazards.

Since we applied Monte Carlo simulation, this is still a further way to discuss about the uncertainties [32], which would be one of future works. Additionally, we plan to further develop the combined model so that it can be applied to more complex cascading problems such as the investigation of the nexus of water, energy, health care and food-supplying systems, including socio-economic considerations [33-38].

Author Contributions: Conceptualization, Y.Y., D.V.V. and Q.Z.; methodology, Y.Y., D.V.V. and Q.Z.; software, Y.Y.; validation, Y.Y.; formal analysis, Y.Y.; investigation, Y.Y.; writing-original draft preparation, Y.Y. and Q.Z.; writing-review and editing, D.V.V., Q.Z. and D.Y.; visualization, Y.Y.; supervision, project administration and funding, Q.Z. and D.V.V. All authors have read and agreed to the published version of the manuscript.

Funding: This research was funded by EPSRC UK.

Institutional Review Board Statement: Not applicable.

Informed Consent Statement: Not applicable. 
Data Availability Statement: Data is available on request.

Acknowledgments: The project is supported by the EPSRC Impact Acceleration Account Project 'Improving Resilience of Coastal Communities' (IRoCC). Thanks for the support from selected town community. Thanks to SEPA, Scottish Water, Scottish \& Southern Electricity Networks, Department for Business, Energy and Industrial Strategy (UK), and Site Investigation Services company for providing data. Special thanks to L. Beevers and P. McCallum, both from Heriot Watt University, for discussions about the flood model and the calculation of electricity consumption, respectively.

Conflicts of Interest: The authors declare no conflict of interest.

\section{Appendix A}

The flood model setup and its connection to infrastructure network is shown in Figure A1. The sensitivity of network model scenarios is listed in Table A1.

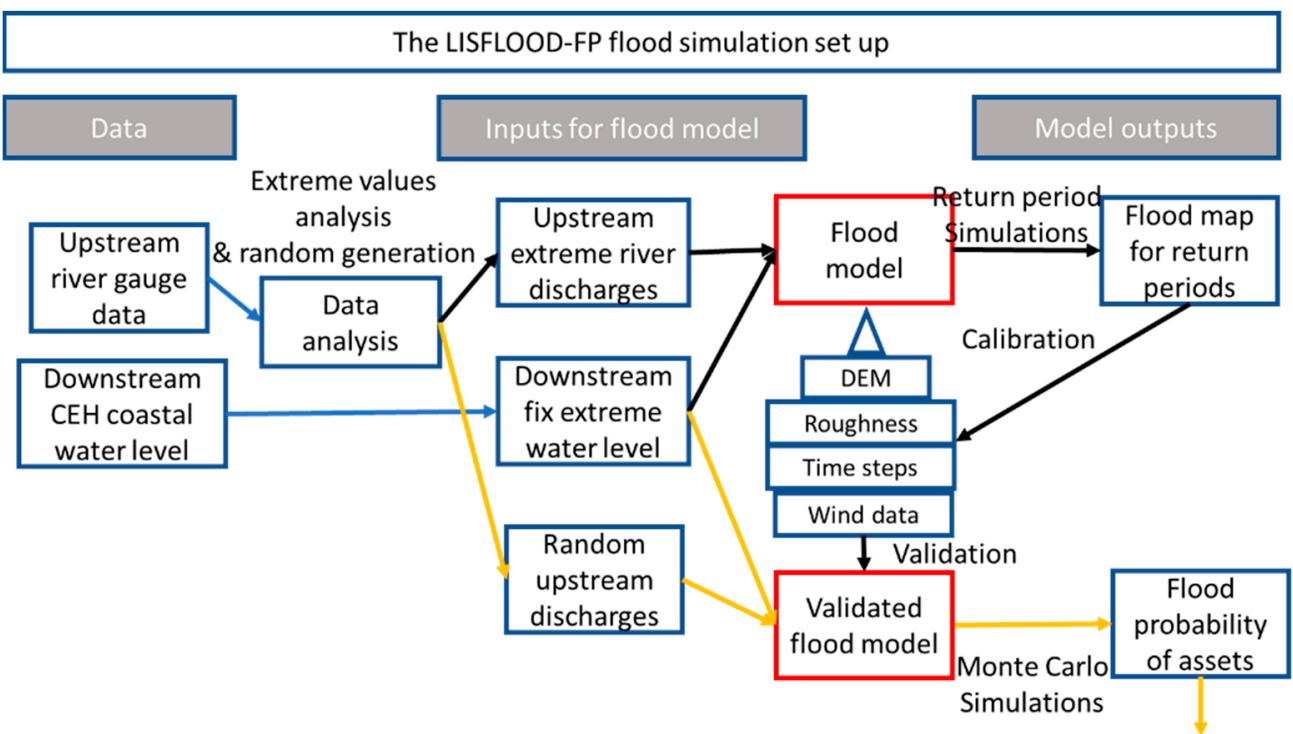

To Infrastructure network

Figure A1. The flow chat of LISFLOOD-FP simulations set ups and its connection to the infrastructure network model. The black lines stand for the procedure of model calibration and validation and yellow lines indicate for Monte Carlo simulation scenarios. The red rectangles are the LISFLOOD-FP model.

Table A1. The scenarios of the electricity supply disruption for the network in Figure 3.

\begin{tabular}{|c|c|c|c|c|c|}
\hline Scenarios & $\begin{array}{l}\text { No. of Steps } \\
\text { in Unmet } \\
\text { Demand Cost } \\
\text { Profile }\end{array}$ & Cost Profile & $\begin{array}{l}\text { Supply to Demand Ratio for } \\
\text { the 1st Node with Interrupted } \\
\text { Supply (Node 15) }\end{array}$ & $\begin{array}{l}\text { Supply to Demand Ratio } \\
\text { for the 2nd Node with } \\
\text { Interrupted Supply }\end{array}$ & $\begin{array}{l}\text { Last Nodes Experiencing } \\
\text { the Supply Interuption }\end{array}$ \\
\hline S0 & 1 & / & $0 \%$ in $3 \mathrm{~h}$ after accident & Node $12: 80 \%$ in $3 \mathrm{~h}$ & $4,7,9:$ in $10 \mathrm{~h}$ \\
\hline S1 & 2 & & & & \\
\hline S11 & & {$[0.8,0.2]$} & $20 \%$ in $3 \mathrm{~h}$ & Node $12: 40 \%$ in $2 \mathrm{~h}$ & $4,7,8,9:$ in $8 \mathrm{~h}$ \\
\hline S12 & & {$[0.6,0.4]$} & $40 \%$ in $3 \mathrm{~h}$ & $\begin{array}{c}\text { Node } 11: 40 \% \text { in } 3 \mathrm{~h} \text {; Node } \\
\text { 12: } 40 \% \text { in } 3 \mathrm{~h} \text {; Node 3: } 98 \% \\
\text { in } 3 \mathrm{~h}\end{array}$ & $4,5,7,8,9$ : in $6 \mathrm{~h}$ \\
\hline S13 & & {$[0.5,0.5]$} & $50 \%$ in $3 \mathrm{~h}$ & Node $12: 90 \%$ in $2 \mathrm{~h}$ & $4,5,7,8,9$ : in $5 \mathrm{~h}$ \\
\hline S14 & & {$[0.4,0.6]$} & $60 \%$ in $3 \mathrm{~h}$ & Node $12: 70 \%$ in $2 \mathrm{~h}$ & $4,5,7,8,9$ : in $4 \mathrm{~h}$ \\
\hline
\end{tabular}


Table A1. Cont.

\begin{tabular}{|c|c|c|c|c|c|}
\hline Scenarios & $\begin{array}{l}\text { No. of Steps } \\
\text { in Unmet } \\
\text { Demand Cost } \\
\text { Profile }\end{array}$ & Cost Profile & $\begin{array}{l}\text { Supply to Demand Ratio for } \\
\text { the 1st Node with Interrupted } \\
\text { Supply (Node 15) }\end{array}$ & $\begin{array}{l}\text { Supply to Demand Ratio } \\
\text { for the 2nd Node with } \\
\text { Interrupted Supply }\end{array}$ & $\begin{array}{c}\text { Last Nodes Experiencing } \\
\text { the Supply Interuption }\end{array}$ \\
\hline S15 & & {$[0.2,0.8]$} & $80 \%$ in $3 \mathrm{~h}$ & $\begin{array}{l}\text { Node } 11: 80 \% \text { in } 2 \mathrm{~h} \text {; Node } \\
\text { 12: } 80 \% \text { in } 2 \mathrm{~h} \text {; Node } 2: 80 \% \\
\text { in } 2 \mathrm{~h} \text {; Node } 3: 80 \% \text { in } 2 \mathrm{~h}\end{array}$ & $\begin{array}{l}\text { all nodes start to } \\
\text { interupt in } 3 \mathrm{~h}\end{array}$ \\
\hline S2 & 3 & & & & \\
\hline S21 & & {$[0.6,0.2,0.2]$} & $40 \%$ in $2 \mathrm{~h}$ then $20 \%$ in $8 \mathrm{~h}$; & $\begin{array}{c}\text { Node } 11: 40 \% \text { in } 3 \mathrm{~h} \text {; Node } \\
\text { 12: } 40 \% \text { in } 3 \text { h; Node } 3: 90 \% \\
\text { in } 3 \mathrm{~h}\end{array}$ & $4,7,8,9:$ in $6 \mathrm{~h}$ \\
\hline $\mathrm{S} 22$ & & {$[0.4,0.4,0.2]$} & $60 \%$ in $2 \mathrm{~h}$ then $20 \%$ in $8 \mathrm{~h}$; & Node $12: 70 \%$ in $2 \mathrm{~h}$ & $4,5,7,8,9:$ in $6 \mathrm{~h}$ \\
\hline S23 & & {$[0.2,0.6,0.2]$} & $80 \%$ in $2 \mathrm{~h}$ latter then $20 \%$ in $4 \mathrm{~h}$; & $\begin{array}{l}\text { Node } 11: 80 \% \text { in } 2 \mathrm{~h} \text {; Node } \\
\text { 12: } 80 \% \text { in } 2 \mathrm{~h} \text {; Node } 2: 80 \% \\
\text { in } 2 \mathrm{~h} \text {; Node } 3: 80 \% \text { in } 2 \mathrm{~h}\end{array}$ & $4,5,7,8,9:$ in $4 \mathrm{~h}$ \\
\hline $\mathrm{S} 24$ & & {$[0.1,0.8,0.1]$} & $90 \%$ in $2 \mathrm{~h}$ latter then $10 \%$ in $4 \mathrm{~h}$; & All nodes: $90 \%$ in $2 \mathrm{~h}$ & $\begin{array}{l}\text { all nodes start to } \\
\text { interupt in } 3 \mathrm{~h}\end{array}$ \\
\hline S25 & & {$[0.4,0.2,0.4]$} & $60 \%$ in $2 \mathrm{~h}$ latter then $40 \%$ in $6 \mathrm{~h}$; & Node $12: 60 \%$ in $2 \mathrm{~h}$ & $4,5,7,8,9:$ in $4 \mathrm{~h}$ \\
\hline S26 & & {$[0.2,0.2,0.6]$} & $80 \%$ in $2 \mathrm{~h}$ latter then $60 \%$ in $4 \mathrm{~h}$; & $\begin{array}{l}\text { Node } 11: 80 \% \text { in } 2 \mathrm{~h} \text {; Node } \\
\text { 12: } 80 \% \text { in } 2 \mathrm{~h} \text {; Node } 2: 80 \% \\
\text { in } 2 \mathrm{~h} \text {; Node } 3: 80 \% \text { in } 2 \mathrm{~h}\end{array}$ & $\begin{array}{l}\text { all nodes start to } \\
\text { interupt in } 3 \mathrm{~h}\end{array}$ \\
\hline S27 & & {$[0.1,0.1,0.8]$} & $90 \%$ in $2 \mathrm{~h}$ latter then $10 \%$ in $4 \mathrm{~h}$; & All nodes: $90 \%$ in $2 \mathrm{~h}$ & $\begin{array}{l}\text { all nodes start to } \\
\text { interupt in } 2 \mathrm{~h}\end{array}$ \\
\hline S3 & 4 & & & & \\
\hline S31 & & {$[0.4,0.2,0.2,0.2]$} & $60 \%$ in $2 \mathrm{~h}$ latter then $40 \%$ in $6 \mathrm{~h}$; & Node $12: 60 \%$ in $2 \mathrm{~h}$ & $4,5,7,8,9:$ in $5 \mathrm{~h}$ \\
\hline S32 & & {$[0.2,0.4,0.2,0.2]$} & $80 \%$ in $2 \mathrm{~h}$ latter then $20 \%$ in $4 \mathrm{~h}$; & $\begin{array}{l}\text { Node } 11: 80 \% \text { in } 2 \mathrm{~h} \text {; Node } \\
\text { 12: } 80 \% \text { in } 2 \mathrm{~h} \text {; Node } 2: 80 \% \\
\text { in } 2 \mathrm{~h} \text {; Node } 3: 80 \% \text { in } 2 \mathrm{~h}\end{array}$ & $\begin{array}{l}\text { all nodes start to } \\
\text { interupt in } 3 \mathrm{~h}\end{array}$ \\
\hline S33 & & {$[0.2,0.2,0.4,0.2]$} & $80 \%$ in $2 \mathrm{~h}$ latter then $20 \%$ in $6 \mathrm{~h}$; & $\begin{array}{l}\text { Node } 11: 80 \% \text { in } 2 \mathrm{~h} \text {; Node } \\
\text { 12: } 80 \% \text { in } 2 \mathrm{~h} \text {; Node } 2: 80 \% \\
\text { in } 2 \mathrm{~h} \text {; Node } 3: 80 \% \text { in } 2 \mathrm{~h}\end{array}$ & $\begin{array}{l}\text { all nodes start to } \\
\text { interupt in } 3 \mathrm{~h}\end{array}$ \\
\hline S34 & & {$[0.2,0.2,0.2,0.4]$} & $80 \%$ in $2 \mathrm{~h}$ latter then $40 \%$ in $6 \mathrm{~h}$; & $\begin{array}{l}\text { Node } 11: 80 \% \text { in } 2 \mathrm{~h} \text {; Node } \\
\text { 12: } 80 \% \text { in } 2 \mathrm{~h} \text {; Node } 2: 80 \% \\
\text { in } 2 \mathrm{~h} \text {; Node } 3: 80 \% \text { in } 2 \mathrm{~h}\end{array}$ & $\begin{array}{l}\text { all nodes start to } \\
\text { interupt in } 3 \mathrm{~h}\end{array}$ \\
\hline S35 & & {$[0.2,0.2,0.3,0.3]$} & $80 \%$ in $2 \mathrm{~h}$ latter then $30 \%$ in $6 \mathrm{~h}$; & $\begin{array}{l}\text { Node } 11: 80 \% \text { in } 2 \mathrm{~h} \text {; Node } \\
\text { 12: } 80 \% \text { in } 2 \mathrm{~h} \text {; Node } 2: 80 \% \\
\text { in } 2 \mathrm{~h} \text {; Node } 3: 80 \% \text { in } 2 \mathrm{~h}\end{array}$ & $\begin{array}{l}\text { all nodes start to } \\
\text { interupt in } 3 \mathrm{~h}\end{array}$ \\
\hline S36 & & {$[0.2,0.3,0.2,0.3]$} & the same but $70 \%$ in $6 \mathrm{~h}$ & the same & $\begin{array}{l}\text { all nodes start to } \\
\text { interupt in } 3 \mathrm{~h}\end{array}$ \\
\hline S37 & & {$[0.3,0.3,0.2,0.2]$} & $70 \%$ in $2 \mathrm{~h}$ latter then $20 \%$ in $6 \mathrm{~h}$; & $\begin{array}{c}\text { Node 11: } 80 \% \text { in } 2 \mathrm{~h} \text {; Node } \\
\text { 12: } 80 \% \text { in } 2 \mathrm{~h} ;\end{array}$ & $\begin{array}{l}\text { all nodes start to } \\
\text { interupt in } 4 \mathrm{~h}\end{array}$ \\
\hline $\mathrm{S} 4$ & 5 & & & & \\
\hline S41 & & $\begin{array}{c}{[0.2,0.2,0.2,0.2} \\
0.2]\end{array}$ & $\begin{array}{l}80 \% \text { in } 2 \mathrm{~h} \text { latter then drop } 20 \% \\
\text { in every } 2 \mathrm{~h} \text {; }\end{array}$ & $\begin{array}{l}\text { Node } 11: 80 \% \text { in } 2 \mathrm{~h} \text {; Node } \\
\text { 12: } 80 \% \text { in } 2 \mathrm{~h} \text {; Node } 2: 80 \% \\
\text { in } 2 \mathrm{~h} \text {; Node } 3: 80 \% \text { in } 2 \mathrm{~h}\end{array}$ & $\begin{array}{l}\text { All nodes start to } \\
\text { interupt in } 3 \mathrm{~h}\end{array}$ \\
\hline
\end{tabular}

\section{References}

1. Ouyang, M. Review on modelling and simulation of interdependent critical infrastructure systems. Reliab. Eng. Syst. Saf. 2014, 121, 43-60. [CrossRef]

2. Haimes, Y.Y. Road map for modeling risks of terrorism to homeland. J. Infrastruct. Syst. 2002, 8, 35-41. [CrossRef]

3. Petri, C.A. Communication with Automata. Ph.D. Thesis, Technische Universität Darmstadt, Darmstadt, Germany, 1962.

4. Hadjsaid, N.; Tranchita, C.; Rozel, B.; Viziteu, M.; Caire, R. Modeling cyber and physical interdependencies-Application in ICT and power grids. In Proceedings of the 2009 Power Systems Conference and Exposition, Seattle, WA, USA, 15-18 March 2009; pp. 1-6.

5. Val, D.V.; Holden, R.; Nodwell, S. Probabilistic analysis of interdependent infrastructures subjected to weather-related hazards. Civ. Eng. Environ. Syst. 2014, 31, 140-152. [CrossRef] 
6. Lee, E.E.; Mitchell, J.E.; Wallace, W.A. Restoration of Services in Interdependent Infrastructure Systems: A Network Flows Approach. IEEE Trans. Syst. Man Cybern. Part C Appl. Rev. 2007, 37, 1303-1317. [CrossRef]

7. Svendsen, N.; Wolthusen, S. Connectivity Models of Interdependency in Mixed-type Critical Infrastructure Networks. Inf. Secur. Tech. Rep. 2007, 12, 44-55. [CrossRef]

8. Bates, P.D.; De Roo, A.P.J. A simple raster-based model for flood inundation simulation. J. Hydrol. 2000, 236, 54-77. [CrossRef]

9. Bates, P.D.; Horritt, M.S.; Fewtrell, T.J. A simple inertial formulation of the shallow water equations for efficient two-dimensional flood inundation modelling. J. Hydrol. 2010, 387, 33-45. [CrossRef]

10. Douglas, E.; Jacobs, J.; Hayhoe, K.; Silka, L.; Daniel, J.; Collins, M.; Alipour, A.; Anderson, B.; Hebson, C.; Mecray, E.; et al. Progress and challenges in incorporating climate change information into transportation research and design. J. Infrastruct. Syst. 2017, 23, 04017018. [CrossRef]

11. Pant, R.; Thacker, S.; Hall, J.W.; Alderson, D.; Barr, S. Critical infrastructure impact assessment due to flood exposure. J. Flood Risk Manag. 2018, 11, 22-33. [CrossRef]

12. Serre, D.; Heinzlef, C. Assessing and mapping urban resilience to floods with respect to cascading effects through critical infrastructure networks. Int. J. Disaster Risk Reduct. 2018, 30, 235-243. [CrossRef]

13. Park, J.; Seager, T.P.; Rao, P.S.C.; Convertino, M.; Linkov, I.; Thacker, S.; Hall, J.W.; Alderson, D.; Barr, S. Integrating Risk and Resilience Approaches to Catastrophe Management in Engineering Systems. Risk Anal. 2013, 33, 356-367. [CrossRef] [PubMed]

14. Zimmerman, R.; Zhu, Q.; Francisco, L.; Guo, Z. Conceptual modelling framework to integrate resilient and interdependent infrastructure in extreme weather. J. Infrastruct. Syst. 2017, 23, 04017034. [CrossRef]

15. Ahuja, R.K.; Magnanti, T.L.; Orlin, J.B. Network Flows: Theory, Algorithms and Applications; Prentice-Hall: Englewood Cliffs, NJ, USA, 1993.

16. Puno, G.R.; Amper, R.A.L.; Opiso, E.M.; Cipriano, J.A.B. Mapping and analysis of flood scenarios using numerical models and GIS techniques. Spat. Inf. Res. 2020, 28, 215-226. [CrossRef]

17. Lyu, H.-M.; Shen, S.-L.; Yang, J.; Yin, Z.-Y. Inundation analysis of metro systems with the storm water management model incorporated into a geographical information system: A case study in Shanghai. Hydrol. Earth Syst. Sci. 2019, 23, $4293-4307$. [CrossRef]

18. Bisht, D.S.; Chatterjee, C.; Kalakoti, S.; Upadhyay, P.; Sahoo, M.; Panda, A. Modeling urban floods and drainage using SWMM and MIKE URBAN: A case study. Nat. Hazards 2016, 84, 749-776. [CrossRef]

19. Wong, P.P.; Losada, I.J.; Gattuso, J.-P.; Hinkel, J.; Khattabi, A.; McInnes, K.L.; Saito, Y.; Sallenger, A. Coastal systems and low-lying areas. In Climate Change 2014: Impacts, Adaptation, and Vulnerability. Part A: Global and Sectoral Aspects. Contribution of Working Group II to the Fifth Assessment Report of the Intergovernmental Panel on Climate Change; Field, C.B., Barros, V.R., Dokken, D.J., Mach, K.J., Mastrandrea, M.D., Bilir, T.E., Chatterjee, M., Ebi, K.L., Estrada, Y.O., Genova, R.C., et al., Eds.; Cambridge University Press: Cambridge, UK; New York, NY, USA, 2014; pp. 361-409.

20. Arns, A.; Wahl, T.; Dangendorf, S.; Jensen, J. The impact of sea level rise on storm surge water levels in the northern part of the German Bight. Coast. Eng. 2015, 96, 118-131. [CrossRef]

21. Wahl, T.; Jain, S.; Bender, J.; Meyers, S.D.; Luther, M.E. Increasing risk of compound flooding from storm surge and rainfall for major US cities. Nat. Clim. Chang. 2015, 5, 1093-1097. [CrossRef]

22. Hendry, A.; Haigh, I.D.; Nicholls, R.J.; Winter, H.; Neal, R.; Wahl, T.; Joly-Laugel, A.; Darby, S.E. Assessing the characteristics and drivers of compound flooding events around the UK coast. Hydrol. Earth Syst. Sci. 2019, 23, 3117-3139. [CrossRef]

23. Jarvis, S.G.; Henrys, P.A.; Redhead, J.W.; Da Silva Osório, B.M.; Pywell, R.F. CEH Land Cover plus: Pesticides $2012-2016$ (England and Wales). NERC Environ. Inf. Data Cent. 2019. (Dataset). [CrossRef]

24. Barredo, J.I.; Engelen, G. Land Use Scenario Modeling for Flood Risk Mitigation. Sustainability 2010, 2, 1327-1344. [CrossRef]

25. McMillan, A.; Batstone, C.; Worth, D.; Tawn, J.; Horsburgh, K.; Lawless, D. Coastal Flood Boundary Conditions for UK Mainland and Islands; Technical Report; Environment Agency/Defra: Bristol, UK, 2011.

26. Yin, Y.; Karunarathna, H.; Reeve, D.E. A computational investigation of storm impacts on estuary morphodynamics. J. Mar. Sci. Eng. 2019, 7, 421. [CrossRef]

27. Schumann, G.; Bates, P.D.; Horritt, M.S.; Matgen, P.; Pappenberger, F. Progress in integration of remote sensing-Derived flood extent and stage data and hydraulic models. Rev. Geophys. 2009, 47, RG4001. [CrossRef]

28. Visser-Quinn, A.; Beevers, L.; Collet, L.; Formetta, G.; Smith, K.; Wanders, N.; Thober, S.; Pan, M.; Kumar, R. Spatio-temporal analysis of compound hydro-hazard extremes across the UK. Adv. Water Resour. 2019, 130, 77-90. [CrossRef]

29. Xie, D.; Zou, Q.; Mignone, A.; MacRae, J.D. Coastal flooding from wave overtopping and sea level rise adaptation in the northeastern USA. Coast. Eng. 2019, 150, 39-58. [CrossRef]

30. Xie, D.; Zou, Q.; Cannon, J.W. Application of SWAN+ADCIRC to tide-surge and wave simulation in Gulf of Maine during Patriot's Day storm. Water Sci. Eng. 2016, 9, 33-41. [CrossRef]

31. Zou, Q.; Xie, D. Tide-surge and wave interaction in the Gulf of Maine during an extratropical storm. Ocean. Dyn. 2016, 66, 1715-1732. [CrossRef]

32. Zou, Q.; Chen, Y.; Cluckie, I.; Hewston, R.; Pan, S.; Peng, Z.; Reeve, D. Ensemble prediction of coastal flood risk arising from overtopping by linking meteorological, ocean, coastal and surf zone models. Q. J. R. Meteorol. Soc. 2013, 139, 298-313. [CrossRef]

33. Fekete, A. Critical infrastructure and flood resilience: Cascading effects beyond water. Wiley Interdiscip. Rev. Water 2019, 6, e1370. [CrossRef] 
34. Holden, R.; Val, D.; Burkhard, R.; Nodwell, S.C. A network flow model for interdependent infrastructures at the local scale. Saf. Sci. 2013, 53, 51-60. [CrossRef]

35. Oven, K.J.; Curtis, S.E.; Reaney, S.; Riva, M.; Stewart, M.G.; Ohlemüller, R.; Dunn, C.E.; Nodwell, S.; Dominelli, L.; Holden, R. Climate change and health and social care: Defining future hazard, vulnerability and risk for infrastructure systems supporting older people's health care in England. Appl. Geogr. 2012, 33, 16-24. [CrossRef]

36. Pahl-Wostl, C.; Gorris, P.; Jager, N.; Koch, L.; Lebel, L.; Stein, C.; Venghaus, S.; Withanachchi, S. Scale-related governance challenges in the water-energy-food nexus: Toward a diagnostic approach. Sustain. Sci. 2021, 16, 615-629. [CrossRef]

37. Xian, S.; Yin, J.; Lin, N.; Oppenheimer, M. Influence of risk factors and past events on flood resilience in coastal megacities: Comparative analysis of NYC and Shanghai. Sci. Total Environ. 2018, 610, 1251-1261. [CrossRef] [PubMed]

38. Yu, D.; Yin, J.; Wilby, R.L.; Lane, S.N.; Aerts, J.C.; Lin, N.; Liu, M.; Yuan, H.; Chen, J.; Prudhomme, C.; et al. Disruption of emergency response to vulnerable populations during floods. Nat. Sustain. 2020, 3, 728-736. [CrossRef] 